\title{
miR-711 upregulation induces neuronal cell death after traumatic brain injury
}

\author{
B Sabirzhanov ${ }^{*, 1,2,5}$, BA Stoica, ${ }^{*, 2,5}$, Z Zhao ${ }^{1,2}$, DJ Loane ${ }^{1,2}, \mathrm{~J} \mathrm{Wu}^{1,2}$, SG Dorsey ${ }^{3,4}$ and Al Faden ${ }^{1,2}$
}

Traumatic brain injury (TBI) is a leading cause of mortality and disability. MicroRNAs (miRs) are small noncoding RNAs that negatively regulate gene expression at post-transcriptional level and may be key modulators of neuronal apoptosis, yet their role in secondary injury after TBI remains largely unexplored. Changes in miRs after controlled cortical impact (CCl) in mice were examined during the first $72 \mathrm{~h}$ using miR arrays and qPCR. One selected miR (711) was examined with regard to its regulation and relation to cell death; effects of miR-711 modulation were evaluated after $\mathrm{CCl}$ and using in vitro cell death models of primary cortical neurons. Levels of miR-711 were increased in the cortex early after TBI and in vitro models through rapid upregulation of miR-711 transcription (pri-miR-711) rather than catabolism. Increases coincided with downregulation of the pro-survival protein Akt, a predicted target of miR-711, with sequential activation of forkhead box 03 (Fox03)a/glycogen synthase kinase 3 (GSK3) $\alpha / \beta$, pro-apoptotic BH3-only molecules PUMA (Bcl2-binding component 3) and Bim (Bcl2-like 11 (apoptosis facilitator)), and mitochondrial release of cytochrome $c$ and AIF. miR-711 and Akt (mRNA) co-immunoprecipitated with the RNA-induced silencing complex (RISC). A miR-711 hairpin inhibitor attenuated the apoptotic mechanisms and decreased neuronal death in an Aktdependent manner. Conversely, a miR-711 mimic enhanced neuronal apoptosis. Central administration of the miR-711 hairpin inhibitor after TBI increased Akt expression and attenuated apoptotic pathways. Treatment reduced cortical lesion volume, neuronal cell loss in cortex and hippocampus, and long-term neurological dysfunction. miR-711 changes contribute to neuronal cell death after TBI, in part by inhibiting Akt, and may serve as a novel therapeutic target.

Cell Death and Differentiation (2016) 23, 654-668; doi:10.1038/cdd.2015.132; published online 16 October 2015

MicroRNAs (miRs) are short (20-23 nucleotide) noncoding RNAs that negatively regulate gene expression at the posttranscriptional level by binding to the $3^{\prime}$-untranslated region (UTR) of target mRNAs, leading to their degradation and/or translational inhibition. ${ }^{1}$ Although miRs have been implicated in the pathophysiology of central nervous system (CNS) disorders $^{2-4}$ and may modulate neuronal cell death pathways, ${ }^{5}$ few have been directly evaluated at a mechanistic level in traumatic brain injury (TBI). ${ }^{6,7}$

TBI initiates regulated neuronal death mechanisms that significantly contribute to neuronal loss and neurological dysfunction. ${ }^{8}$ Proteins of the $\mathrm{Bcl} 2$ family, which regulate neuronal death in response to many insults, include prosurvival proteins (e.g., $\mathrm{Bcl} 2$ and $\mathrm{BclxL}$ ), as well as proapoptotic multi-domain (e.g., Bax and Bak), and BH3-only domain proteins (e.g., PUMA (Bcl2-binding component 3), Noxa, Bim (Bcl2-like 11 (apoptosis facilitator)) and Bid). ${ }^{9} \mathrm{BH} 3-$ only proteins promote neuronal cell death by causing mitochondrial outer membrane permeabilization and the release of mitochondrial apoptogenic proteins such as cytochrome $\mathrm{C}$ and apoptosis inducing factor-1 (AIF-1). ${ }^{10,11}$ $\mathrm{BH} 3-$ only proteins $^{12}$ have been implicated in neuronal cell death after CNS injury, including TBI. ${ }^{13,14}$ In contrast, Akt (protein kinase B) promotes neuronal survival by phosphorylating/inactivating pro-apoptotic proteins such as forkhead transcription factor FoxO3 and GSK3 $\beta$ that are important initiators of $\mathrm{BH} 3$-only protein expression. ${ }^{15-17}$ Akt pathway inhibition leads to dephosphorylation/activation of FoxO3a and induction of its pro-apoptotic target genes including PUMA and Bim. ${ }^{18,19}$

The present study tested the hypothesis that TBI-induced changes of selected miRs can initiate cell death pathways that result in neuronal loss and neurological deficits. We show increased brain levels of miR-711 in the first $72 \mathrm{~h}$ after controlled cortical impact $(\mathrm{CCl})$, a period associated with maximal secondary tissue injury. ${ }^{8}$ Using neuronal cell death models in vitro and after $\mathrm{TBI}$, we demonstrate that miR-711 acts through its proposed target Akt to activate FoxO3a/ GSK3 $\beta$, resulting in upregulation of PUMA and Bim to induce neuronal cell death and neurological dysfunction.

\footnotetext{
${ }^{1}$ Department of Anesthesiology, University of Maryland School of Medicine, Baltimore, MD, USA; ${ }^{2}$ Center for Shock, Trauma, and Anesthesiology Research (STAR), University of Maryland School of Medicine, Baltimore, MD, USA ; ${ }^{3}$ University of Maryland School of Nursing, Baltimore, MD, USA and ${ }^{4}$ Program in Neuroscience, University of Maryland, Baltimore, MD, USA

*Corresponding author: B Sabirzhanov, Department of Anesthesiology, University of Maryland School of Medicine, 655 West Baltimore Street, Room \#6-010, Baltimore 21201, MD, USA. Tel: +1 410706 5185; Fax: +1 410706 1639; E-mail: bsabirzhanov@anes.umm.edu

or BA Stoica, Department of Anesthesiology, University of Maryland School of Medicine, Bressler Research Building (BRB), 655 West Baltimore Street, Room \#6-015, Baltimore 21201, MD, USA. Tel: +1 410706 5186; Fax: +1 410706 1639; E-mail: bstoica@anes.umm.edu

${ }^{5}$ These authors contributed equally to this work.

Abbreviations: AKT, v-akt murine thymoma viral oncogene homolog 1; FoxO3, forkhead box O3; GSK3, glycogen synthase kinase 3; PUMA, Bcl2-binding component 3; Bim, Bcl2-like 11 (apoptosis facilitator); Trib3, tribbles pseudokinase 3; PARP, poly-(ADP-ribose) polymerase; AIF-1, apoptosis inducing factor-1; LDH, lactate dehydrogenase

Received 13.4.15; revised 18.8.15; accepted 03.9.15; Edited by Y Shi; published online 16.10.15
} 


\section{Results}

miR-711 is upregulated in the injured cortex after TBI. We profiled miRs expression in the injured cortex of mice exposed to moderate-level $\mathrm{CCl}$ using miRNA array as described. $^{20} \mathrm{TBI}$ significantly upregulated the level of miR-711 in brain (Figure 1a). We also performed a detailed expression profiling of miR-711 in the injured cortex using qPCR, and observed a rapid upregulation of miR-711 starting as early as $1 \mathrm{~h}$ post-injury, peaking at $6 \mathrm{~h}$ and persisting through $72 \mathrm{~h}$ (Figure 1a).

miR-711 is upregulated in models of neuronal cell death. To explore the putative mechanisms of $\mathrm{miR}$ regulation of neuronal cell death we used several in vitro models including etoposide and staurosporine-induced apoptosis in cortical neurons. ${ }^{21}$ miR-711 levels were determined by qPCR at different time points. Our data demonstrate significant miR-711 elevations early as $3 \mathrm{~h}$ after apoptosis induction in etoposide and staurosporine models (Figures $1 \mathrm{~b}$ and $\mathrm{c}$ ). We observed similar patterns of miR-711 expression in C2-ceramide and camptothecin models of neuronal cell death (data not shown).

miR-711 promotes neuronal cell death and caspase-3 activation. We used miR mimics to examine the role of miR-711 in the regulation of neuronal cell death. Transfection with miR-711 mimics alone significantly increased neuronal cell death and caspase-3 activity in a dose-dependent manner (Figures 1d and f). To test the hypothesis that miR-711 upregulation has a significant role in neuronal apoptosis rat cortical neurons (RCNs) were transfected with miR-711 hairpin inhibitor or negative control hairpin inhibitor followed by treatment with etoposide or staurosporine. We observed a significant and dose-dependent decrease in etoposide and/or staurosporine-induced neuronal cell death (lactate dehydrogenase (LDH) assay) and caspase-3 activity in RCNs transfected with miR-711 hairpin inhibitors (Figures 1d and g).

miR-711 hairpin inhibitor attenuates molecular mechanisms of neuronal apoptosis. To test the ability of miR-711 hairpin inhibitor to attenuate apoptosis mechanisms, RCNs were transfected with miR-711 or negative control hairpin inhibitor before etoposide treatment. Western blot demonstrated that PUMA and Bim protein levels were significantly increased by etoposide treatment. In contrast, transfection of RCNs with miR-711 inhibitor downregulated the levels of both proteins (Figures $2 \mathrm{a}$ and $\mathrm{c}$ ). Subcellular fractionation revealed that miR-711 inhibitor reduced etoposide-induced release of AIF and cytochrome $c$ into the cytosol (Figures 2a,d and e). Western blot demonstrated that neurons transfected with miR-711 hairpin inhibitor displayed reduced levels of the cleaved fragment of caspase-3, cleaved poly-(ADP-ribose) polymerase (PARP), and attenuated the decrease of the full length uncleaved fragment of $a$-fodrin $(240 \mathrm{kDa})$ after etoposide treatment (Figures $2 a$ and $\mathrm{f}-\mathrm{h}$ ). miR-711 hairpin inhibitor reduced the levels of both calpain-dependent (150/145 kDa) and caspase-dependent cleavage $(150 / 120 \mathrm{kDa})^{22}$ fragments of $a$-fodrin (Figures $2 a$, i and j).
Akt is rapidly downregulated in the $\mathrm{TBI}$ cortex and in apoptotic neurons following etoposide treatment. We examined Akt expression in the injured cortex using qPCR, and observed rapid downregulation of Akt expression starting as early as $1 \mathrm{~h}$ post-injury (Figure 3a). To explore mechanisms of neuronal cell death we used etoposideinduced model of apoptosis. qPCR demonstrated that expression of Akt was rapidly downregulated after etoposide treatment similar to our in vivo TBI data (Figure 3b).

miR-711 hairpin inhibitor rescued Akt expression after etoposide treatment. To investigate whether miR-711 regulates the Akt/FoxO pathway during neuronal cell death we measured the levels of these proteins in RCNs after etoposide treatment. Western blot showed that levels of Akt and active/phosphorylated Akt decreased after etoposide treatment (Figures $3 \mathrm{c}$ and $\mathrm{f}$ ) relative to both loading control (general phosphorylation) and total Akt (specific phosphorylation). Transfection of RCNs with miR-711 hairpin inhibitors increased levels of both Akt and phosphorylated Akt after etoposide treatment. (Figures $3 \mathrm{c}$ and $\mathrm{f}$ ). The modest (compared with total Akt) decrease in specific Akt phosphorylation suggests that injury-induced modulation of Akt pathways may involve multiple mechanisms. However, the inhibition of Akt expression appears to be the dominant change modulated by miR-711. We observed upregulation of pro-apoptotic Fox03a in total lysates and in nuclear fraction after etoposide treatment (Figures $3 c, g, h$ and $\mathrm{j}$ ). The level of AIF-1 in the nuclear fraction was increased after etoposide treatment. Treatment with miR-711 inhibitor attenuated translocation of FoxO3a and AlF-1 into the nucleus (Figures 3h and j).

Etoposide treatment increased levels of miR-711 and Akt within the RNA-induced silencing complex. One strand of the mature miRNA binds to argonaute (Ago) proteins to form the RNA-induced silencing complex (RISC). miR acts as a template for RISC to recognize and cleave complementary mRNA. miRNA : mRNA target pairs can be purified by the immunoprecipitation of the RISC components to confirm mRNA targets. We used RNA-interacting protein immunoprecipitation (RIP) with Ago2 antibodies to confirm the role of miR-711 in silencing Akt through RISC. RCNs were treated with etoposide, and cells were collected after $6 \mathrm{~h}$ (peak of etoposide-induced miR-711 expression) and subjected to the RIP using Ago2 antibodies. qPCR demonstrated significant and similar increases of miR-711 and Akt mRNA in the RISC complex following etoposide treatment (Figure 4a).

miR-711 targets $3^{\prime}$-UTRs of Akt mRNA. To test miR-711 regulation of Akt mRNA, we inserted the $3^{\prime}$-UTRs of mouse Akt $3^{\prime}$ of the firefly luciferase gene into pmirGLO plasmid (pmir-Akt). pmirGLO and pmir-Akt were co-transfected with either negative control or miR-711 mimics into RCN. Twentyfour hours after transfection miR-711, but not negative control miR mimic, reduced luciferase activity in cells transfected with pmir-Akt (Figure 4e). These data demonstrate that miR-711 targets the $3^{\prime}$-UTR of Akt mRNA and inhibits expression of Akt. 
a

\section{Controlled cortical impact}

\begin{tabular}{|l|c|c|c|c|l|}
\hline \multirow{2}{*}{} & \multicolumn{4}{|c|}{ Fold change } & \\
\cline { 2 - 6 } & $1 \mathrm{~h}$ & $6 \mathrm{~h}$ & $24 \mathrm{~h}$ & $72 \mathrm{~h}$ & $\mathrm{p}$-value \\
\hline miR-711 & 2.7 & 7.2 & 4.9 & 5.1 & 0.0003 \\
\hline
\end{tabular}

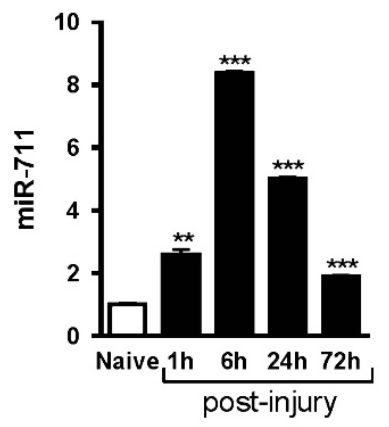

b

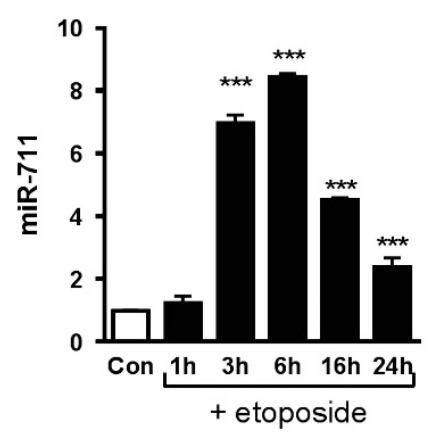

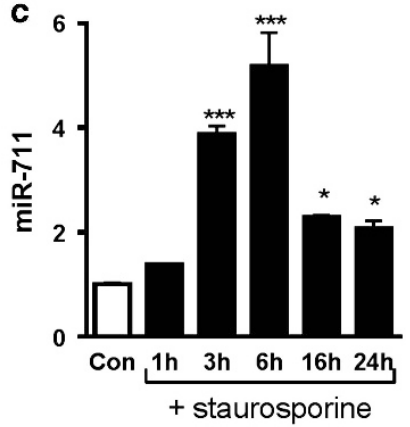
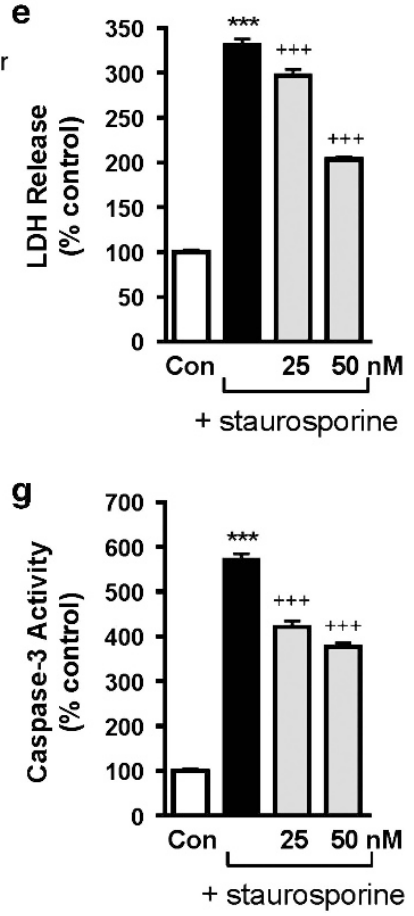
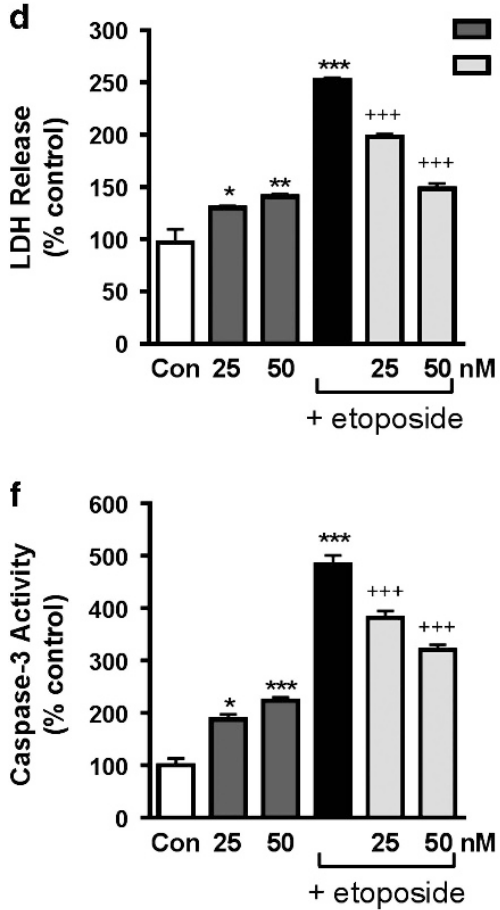
Akt inhibition blocked the neuroprotective effects of the miR-711 hairpin inhibitor. To demonstrate the importance of Akt-modulation for the miR-711-dependent induction of apoptosis we used suboptimal doses of Akt inhibitors, which do not induce or enhance etoposide-induced cell death themselves but rather become effective when cell survival is solely dependent on the Akt pathway. We hypothesize that such conditions occur when miR-711 inhibitors release Akt from inhibitory influence, whereas other etoposide-induced apoptotic pathways are unaffected. We used a direct Akt inhibitor as well as Wortmannin (inhibitor of PI3-K) to confirm a critical role for Akt in miR-711-dependent regulation of neuronal apoptosis. Neuronal death following etoposide treatment (LDH assay) was attenuated by miR-711 hairpin inhibitor (Figures 1d and 4c), and there was no significant increase of neuronal cell death in cells treated with etoposide in combination with Akt inhibitor or Wortmannin (Figure 4b). However, both the Akt inhibitor and Wortmannin significantly decreased phosphorylation of Akt and its downstream targets GSK3a/ $\beta$ (Figure 4d) and increased etoposide-induced neuronal cell death in RCNs that were transfected with miR-711 hairpin inhibitor compared with cells that received miR-711 inhibitor alone (Figure 4c).

miR-711 is rapidly regulated at the transcription stage. To determine whether regulation at the level of transcription or catabolism (degradation of mature miR-711) is responsible for the rapid upregulation of miR-711 during neuronal cell death we used the transcription inhibitor $a$-amanitin $(a-A m)$. $\mathrm{RCNs}$ were treated with $a-A m$ (final concentration $10 \mu \mathrm{g} / \mathrm{ml}$ ), and levels of primary miRNA-711 (pri-mir-711) and mature miR-711 were measured at 1,3 and $6 \mathrm{~h}$ time points by qPCR. a-Am treatment inhibited miR-711 transcription allowing evaluation of the rapid processing of pri-mir-711 (maturation into miR-711) and catabolism of mature miR-711 (degradation; Figure 4f). Etoposide treatment upregulated miR-711 transcription by rapidly increasing levels of pri-mir-711 (a marker of miR transcriptional activity), indicating that increased transcription has an important role in etoposideinduced miR-711 induction (Figure 4g). We examined whether changes in the miR-711 catabolism rate (decrease) have a role in the etoposide-induced miR-711 upregulation. miR-711 was induced by etoposide treatment and $2 \mathrm{~h}$ later RCNs were treated with $a-A m$ to inhibit pri-mir-711 transcription. The rate of decline of pri-mir-711 and miR-711 followed a similar kinetics (Figure 4h) with that observed in a-Amtreated cells (Figure 4f). These data suggest that maturation and catabolism of miR-711 is not changed during etoposideinduced neuronal cell death.

Central administration of miR-711 hairpin inhibitor after TBI increased the level of Akt and phosphorylation of its targets in the injured cortex. We administered $0.5 \mathrm{nmol}$ of miR-711 hairpin inhibitor or negative control miR hairpin inhibitor by intracerebroventricular (i.c.v.) injection at $15 \mathrm{~min}$ after $\mathrm{CCl}$ and examined the expression of Akt, phosphorylated Akt, GSK3 and phosphorylated GSK3 at $24 \mathrm{~h}$ postinjury by western blot. TBI significantly decreased Akt, general phosphorylated Akt and specifically phosphorylated Akt, and markedly downregulated phosphorylation of Akt substrates GSK3a/ $\beta$ (Figures $5 a$ and b). Our findings suggest that the injury-induced regulation of GSK3 is principally at the level of Akt-dependent phosphorylation and not at the expression level. Treatment of TBI mice with a miR-711 hairpin inhibitor significantly upregulated Akt, phosphorylated Akt, GSK3 and phosphorylated GSK3 (Figures 5a and b).

Central administration of miR-711 hairpin inhibitor decreased markers of apoptosis after TBI. Next, we examined the effect of miR-711 inhibitor on apoptosis mechanisms after TBI. TBI resulted in increased levels of pro-apoptotic proteins PUMA and two isoforms of Bim large (L) and small (S), which are regulators of apoptosis upstream of mitochondrial release of AIF-1 and cytochrome $\mathrm{c}$ (Figures $5 \mathrm{a}$ and $\mathrm{c}$ ). The Bim $\mathrm{EL}$ isoform band was undetectable. Treatment with the miR-711 hairpin inhibitor significantly decreased PUMA and Bim after TBI (Figures 5a and c). qPCR data demonstrated that TBI upregulated tribbles pseudokinase 3 (Trib3) expression (Figure 5d).

We examined the levels of key pro-apoptotic proteins, such as apoptotic protease activating factor 1 (APAF1), AIF-1, cytochrome $\mathrm{c}$ and FoxO3a. Neither TBI nor central administration of miR-711 hairpin inhibitor changed the levels of APAF1, cytochrome $\mathrm{c}$ and AIF-1 in whole cell lysates after TBI (data not shown), which is consistent with our previous results. ${ }^{20}$ Western blot revealed that $\mathrm{TBI}$ induced the release of cytochrome $\mathrm{C}$ and AIF-1 from mitochondria to the cytoplasm, and AIF-1 translocation to nucleus (Figures $6 \mathrm{a}$ and b). Treatment with miR-711 hairpin inhibitor significantly reduced $\mathrm{TBl}$-induced release of $\mathrm{AlF}-1$ and cytochrome $c$ into the cytosol and the level of AIF-1 in the nucleus (Figures $6 \mathrm{a}$ and $\mathrm{b}$ ). TBl-induced translocation of FoxO3a in the nucleus was attenuated by miR-711 hairpin inhibitor (Figure 6b). Furthermore, the TBI-induced increased $a$-fodrin cleavage (150/145 kDa fragments) was significantly

Figure $1 \mathrm{miR}-711$ is rapidly upregulated in the TBI cortex and in in vitro models of neuronal cell death. (a) Gene array data for miR-711 levels in the TBI cortex through $72 \mathrm{~h}$ post-injury. Data are presented as fold change compared with uninjured controls. One-way ANOVA, the $P$-values, which were corrected for multiple comparisons, indicate overall significance $(N=3)$. qPCR data for miR-711 confirm the expression pattern after TBI. One-way ANOVA followed by multiple pairwise comparisons using Student-Newman-Keuls post hoc test (one-way ANOVA, SNK post hoc analysis); ${ }^{* \star} P<0.01$; ${ }^{* * \star} P<0.001$ versus naive control $(N=5)$. miR-711 is rapidly upregulated in neurons exposed to cell death inducers etoposide (b) and staurosporine (c). qPCR quantification of miR-711 expressions in RCNs treated with etoposide (b) or staurosporine (c) at the times indicated. One-way ANOVA, SNK post hoc analysis; ${ }^{*} P<0.05$; ${ }^{* \star *} P<0.001$ versus control $(N=6)$. miR-711 promoted neuronal apoptosis and caspase-3 activation. Neurons were transfected with miR-711 mimics, miR-711 hairpin inhibitors or miR negative control hairpin inhibitor (Con), and were treated with etoposide at $4 \mathrm{~h}$ post-transfection. Twenty-four hours later LDH release (d) and caspase-3-like activity (f) were measured. Neurons were transfected with miR-711 hairpin inhibitors or miR negative control hairpin inhibitor (Con) and were treated with staurosporine at $4 \mathrm{~h}$ post-transfection. Twenty-four hours later LDH release (e) and caspase-3-like activity (g) were measured. Data are expressed as percentage of control untreated neurons (mean \pm S.E.M.). One-way ANOVA, SNK post hoc analysis; ${ }^{\star} P<0.05 ;{ }^{* \star} P<0.01 ;{ }^{* \star \star} P<0.001$ versus mock untreated RCN; ${ }^{++} P<0.01$ versus etoposide-treated mock $(N=4)$ 


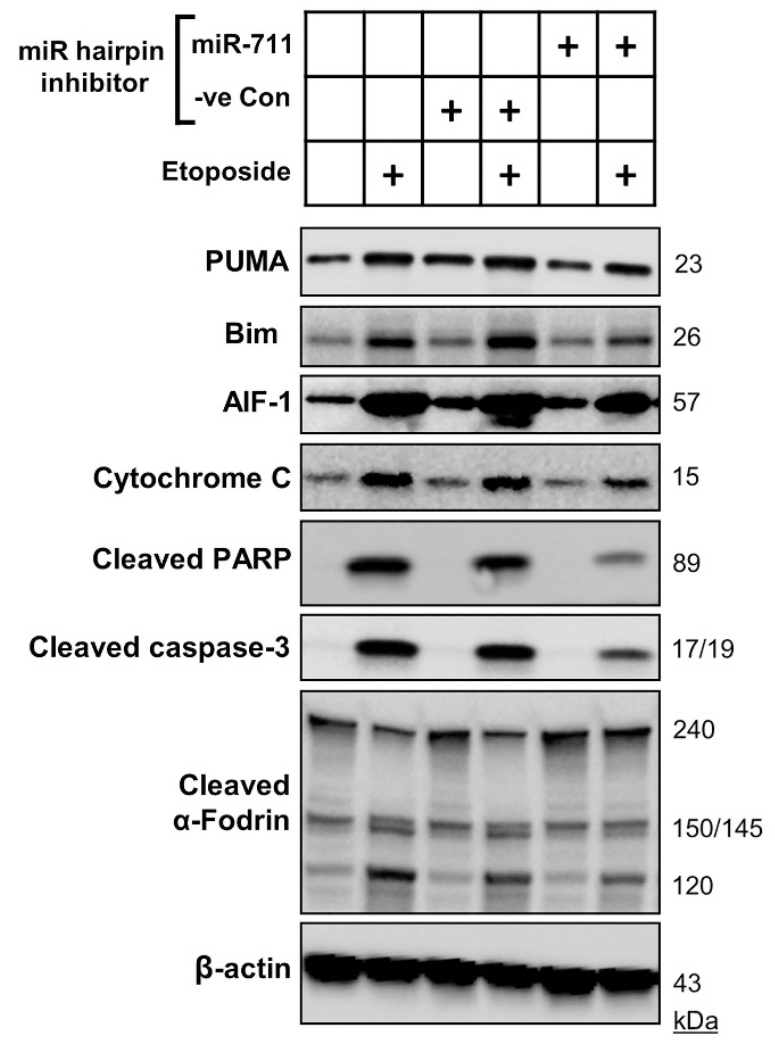

b

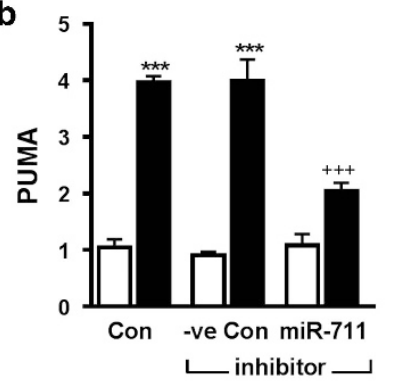

d
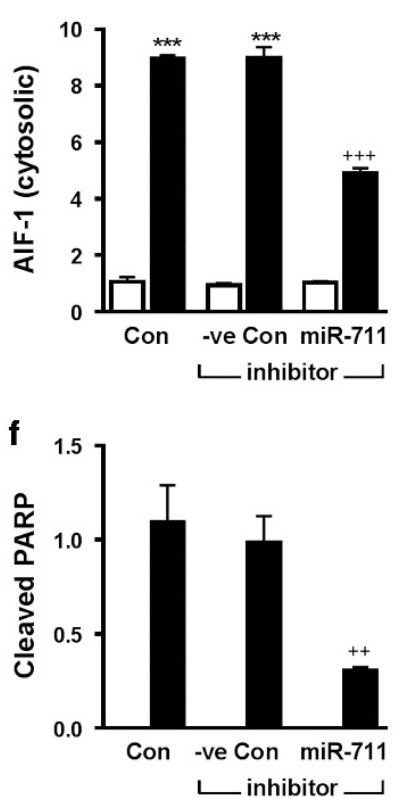

i

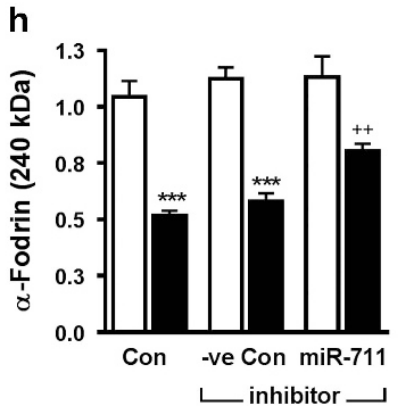

c

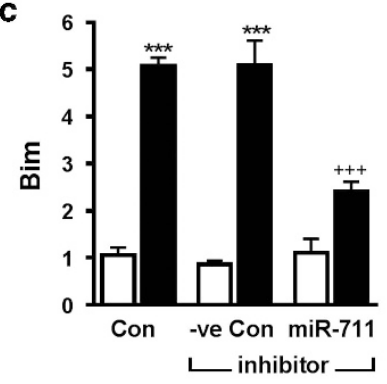

e
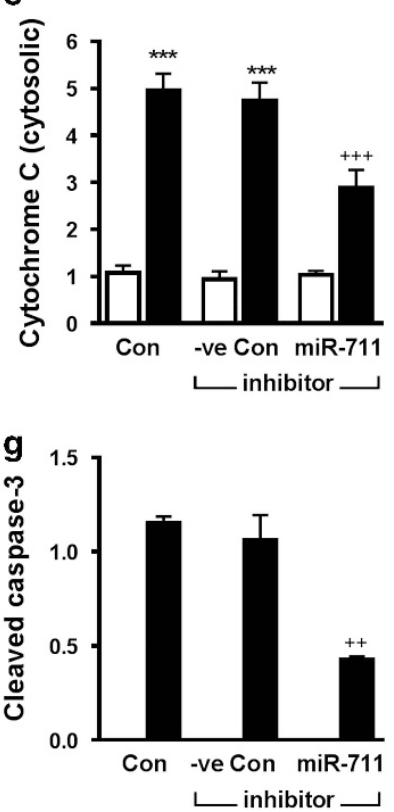

j

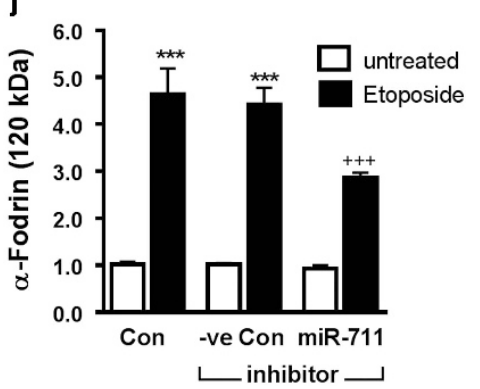

Figure 2 miR-711 hairpin inhibitor attenuates molecular mechanisms of neuronal apoptosis. Neurons were transfected with miR-711 hairpin inhibitors and miR hairpin inhibitors negative control ( - ve Con) and $4 \mathrm{~h}$ later treated with etoposide as described above. Twenty-four hours later whole cell lysates and cytosolic fractions (for the levels of AIF-1 and cytochrome C) were fractioned on SDS-polyacrylamide gel and immunoblotted with antibodies against PUMA, Bim, AIF-1, cytochrome C, cleaved PARP, cleaved caspase-3 and $\alpha$-fodrin (a). Protein levels of PUMA (b), Bim (c), cleaved PARP (f), cleaved caspase-3 (g), and $\alpha$-fodrin (240 kDa (h), $150 / 145 \mathrm{kDa}$ (i), $120 \mathrm{kDa}$ (j)) were quantified in whole cell lysates. Levels of AIF-1 (d) and cytochrome $\mathrm{C}(\mathbf{e})$ were quantified in cytosolic fraction. Protein levels were quantified by densitometry, normalized to $\beta$-actin and presented as fold change compared with control untreated levels. Data represent the mean \pm S.E.M. One-way ANOVA, SNK post hoc analysis; ${ }^{* * *} P<0.001$ versus mock untreated; ${ }^{++} P<0.01 ;{ }^{+++} P<0.001$ versus etoposide-treated mock $(N=4)$

attenuated by treatment with miR-711 hairpin inhibitor (Figure 6c). However, we did not observe differences between the groups in the level of 240 and $120 \mathrm{kDa}$ fragments in this study, which may reflect different patterns of protease activation in the TBI brain as compared with RCNs.

Treatment with miR-711 hairpin inhibitor ameliorated TBI-induced deficits in motor and cognitive functions.
To assess long-term motor function recovery after TBI miR-711 hairpin inhibitor-treated TBI and negative control miR-treated TBI mice were tested on the beam walk task immediately before sham surgery or $\mathrm{CCl}$ and on days $1,3,7$, 14, 21 and 28 post-injury. Repeated measures one-way ANOVA showed a significant effect of treatment $(F(12,182)=$ 14.33, $P<0.0001$ ), and Student-Newman-Keuls post hoc analysis demonstrated significant differences between the 
sham and TBI groups on all days post-injury $(P<0.001$ for each time point; Figure 7a). Notably, administration of the miR-711 hairpin inhibitor significantly improved motor function recovery only on day 21 post-injury $(P<0.05)$ when compared with the negative control miR inhibitor-treated $\mathrm{TBI}$ group. This suggests that the miR-711 inhibitor only modestly improves the motor function. Y-maze spontaneous alternation test was performed on day 14 post-injury to assess spatial working memory. Sham mice showed $83.1 \pm 2.5 \%$ spontaneous alternation, indicative of functional working memory. Negative control miR inhibitor-treated TBI mice showed a significant reduction of spontaneous alternation $(61.0 \pm 3.0 \%)$ compared with sham-injured controls $(P<0.001$; Figure $7 \mathrm{~b})$. miR-711 hairpin inhibitor-treated TBI mice showed significantly increased spontaneous alternation $(70.9 \pm 3.4 \%)$ compared with negative control miR inhibitor-treated TBI group $(P<0.05)$. Next, retention memory was assessed by the NOR test on days 22 and 23 post-injury. Sham mice spent more time than chance (10 s) with the novel object 1 day after training (choice phase), indicating intact memory (Figure 7c). Negative control miR inhibitor-treated TBI mice spent less time with the novel object $(P<0.01$ versus sham), but significantly greater time than chance (Figure 7c). Notably, miR-711 hairpin inhibitor-treated TBI mice returned toward sham-injured control levels and were significantly different from the negative control miR inhibitor-treated TBI group $(P<0.05)$.

Treatment with miR-711 hairpin inhibitor significantly reduced chronic neurodegeneration after TBI. At 28 days post-injury TBI-induced lesion volume was quantified using stereological methods in cresyl violet-stained coronal brain sections from miR-711 hairpin inhibitor-treated and negative control miR inhibitor-treated TBI mice. Treatment with miR-711 hairpin inhibitor significantly reduced the lesion volume compared with the negative control miR inhibitor TBI group (Figures $8 \mathrm{a}$ and b; $P=0.005$; negative control miR inhibitor $=7.34 \pm 0.56 \mathrm{~mm}^{3}$ and miR-711 hairpin inhibitor $=$ $4.91 \pm 0.35 \mathrm{~mm}^{3}$, mean \pm S.E.M.). TBI-induced neuronal loss was also quantified by stereology. Treatment with miR-711 hairpin inhibitor significantly reduced TBI-induced neuronal loss in the cortex and hippocampus (CA2/3 and dentate gyrus subregions; Figures $8 \mathrm{c}$, e and f; $P<0.05$ ).

\section{Discussion}

miR binding is mediated by argonaute proteins within the RISC; depending upon the degree of sequence complementarity, this results in either cleavage of the target mRNA or a reduction in its translational efficiency. ${ }^{23}$ Each miR has many potential targets, thus acting as 'meta-controllers' of brain gene expression. ${ }^{24,25}$ We hypothesize that alteration of selected miRs during the early period after TBI may serve to modulate neuronal cell death pathways. We show that miR-711 is rapidly increased in the injured cortex after TBI, as well as in several neuronal cell death models in vitro.

Etoposide (DNA-damaging agent) and staurosporine (protein kinase inhibitor) induce caspase-dependent and caspase-independent neuronal apoptosis through release of cytochrome $\mathrm{c}$ and AIF from mitochondria into the cytosol, respectively. ${ }^{13}$ Upregulation of miR-711 may be necessary for etoposide and staurosporine-induced neuronal apoptosis, as there is increased survival following administration of miR-711 hairpin inhibitors. miR-711 appears to be sufficient for neuronal cell death, as indicated by decreased survival in neurons treated with miR-711 mimics. Administration of miR-711 hairpin inhibitors attenuated etoposide-induced neuronal apoptosis-resulting in reductions in PUMA, Bim and mitochondria permeabilization, as well as decreased markers of caspase-dependent (caspase-3, PARP and $a$-fodrin cleavage) ${ }^{22}$ and -independent (AIF nuclear translocation ${ }^{11}$ cell death. The specificity of these actions is demonstrated by the lack of effects of miR-711 hairpin inhibitors on other pro-apoptotic Bcl2 family members such as Noxa, Bid or Bax (data not shown).

We demonstrated that downregulation of the miR-23a/27a cluster contributes to neuronal cell death in vitro and in vivo by upregulating the pro-apoptotic Bcl2 family molecules PUMA, Noxa and Bax. ${ }^{20}$ Although Bcl2 family molecules are not among miR-711-predicted targets, Akt is such a target. ${ }^{26} \mathrm{Akt}$ (protein kinase B) can attenuate neuronal apoptosis through phosphorylation and inhibition of caspases, pro-apoptotic Bcl2 family molecules and selected transcription factors (FoxO3a). ${ }^{23}$ Akt phosphorylates and inactivates the members of the forkhead box, class $\mathrm{O}$ transcription factors; conversely, Akt inactivation results in $\mathrm{FoxO} 3$ a dephosphorylation, translocation to the nucleus and transcription of pro-apoptotic proteins such as Bim and PUMA. ${ }^{16}$ A self-amplifying feedforward loop exists between Akt dephosphorylation/inactivation and FoxO dephosphorylation/activation and involves Trib3, a FoxO-induced molecule that interferes with Akt phosphorylation, thus leading to progressive FoxO activation and neuronal death. ${ }^{17}$

In the etoposide-induced apoptosis model, Akt was rapidly decreased (at both mRNA and protein levels). Importantly, we detected increased levels of miR-711 and Akt mRNA in the RISC complex. That this occurred when the cellular Akt levels are low may reflect increased miR-dependent processing of Akt. As miR-711 hairpin inhibitors attenuated Akt downregulation and FoxO3a nuclear translocation, miR-711dependent inhibition of the Akt may have a key role in the initiation of neuronal apoptosis. This is supported by the observation that inhibitors of the Akt pathway reverse the neuroprotective effect of miR-711 inhibition. Studies have shown that the rate of pri-miRs processing (maturation) is relatively constant while the rate of mature miRs catabolism varies with rapid turnover observed with certain neuronal miRs. ${ }^{27}$ Our data show that miR-711 has a fast catabolism rate in RCN and cell injury has no significant impact on the decay rate. Thus, the increased miR-711 levels may reflect a rapid upregulation of miR-711 transcription, as supported by high pri-miRNA levels after etoposide treatment. The study of the mechanisms of miR-711 transcription-either along with its host gene (collagen, type VII, alpha 1) or independently ${ }^{28-30}$ is a goal for future investigation.

The importance of miR-711 changes for TBI-induced activation of neuronal cell death pathways was demonstrated by the significant neuroprotection provided by a miR-711 hairpin inhibitor when administered centrally after $\mathrm{CCl}$. This intervention attenuated TBI-dependent activation of PUMA 
Controlled cortical impact

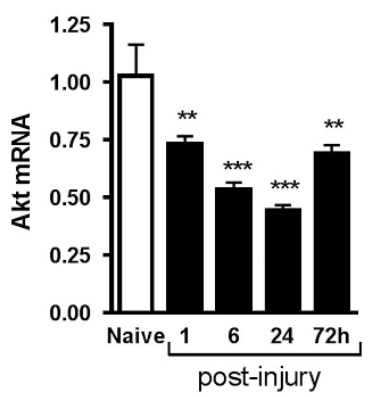

C
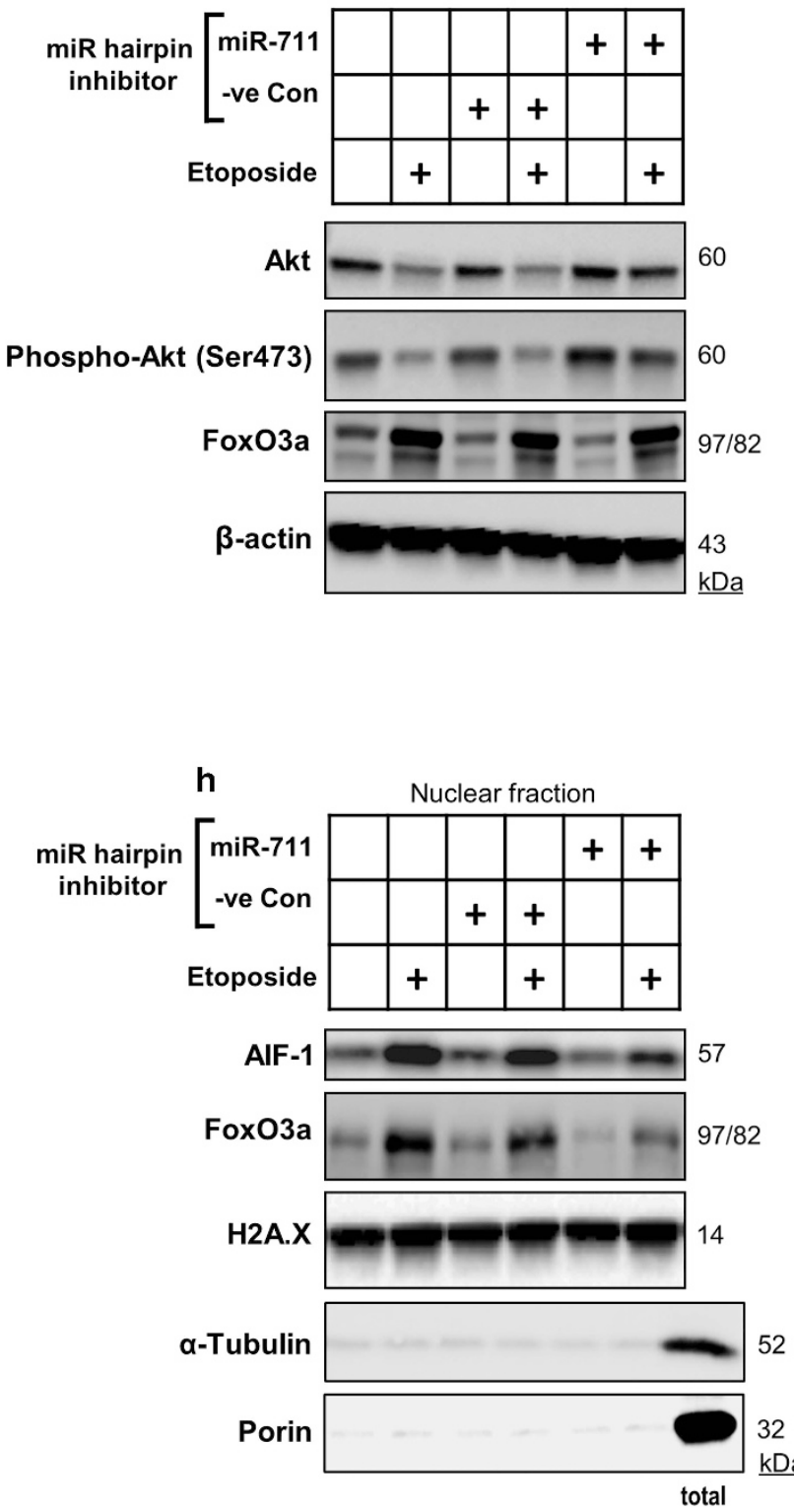

b

In vitro neuronal cell death
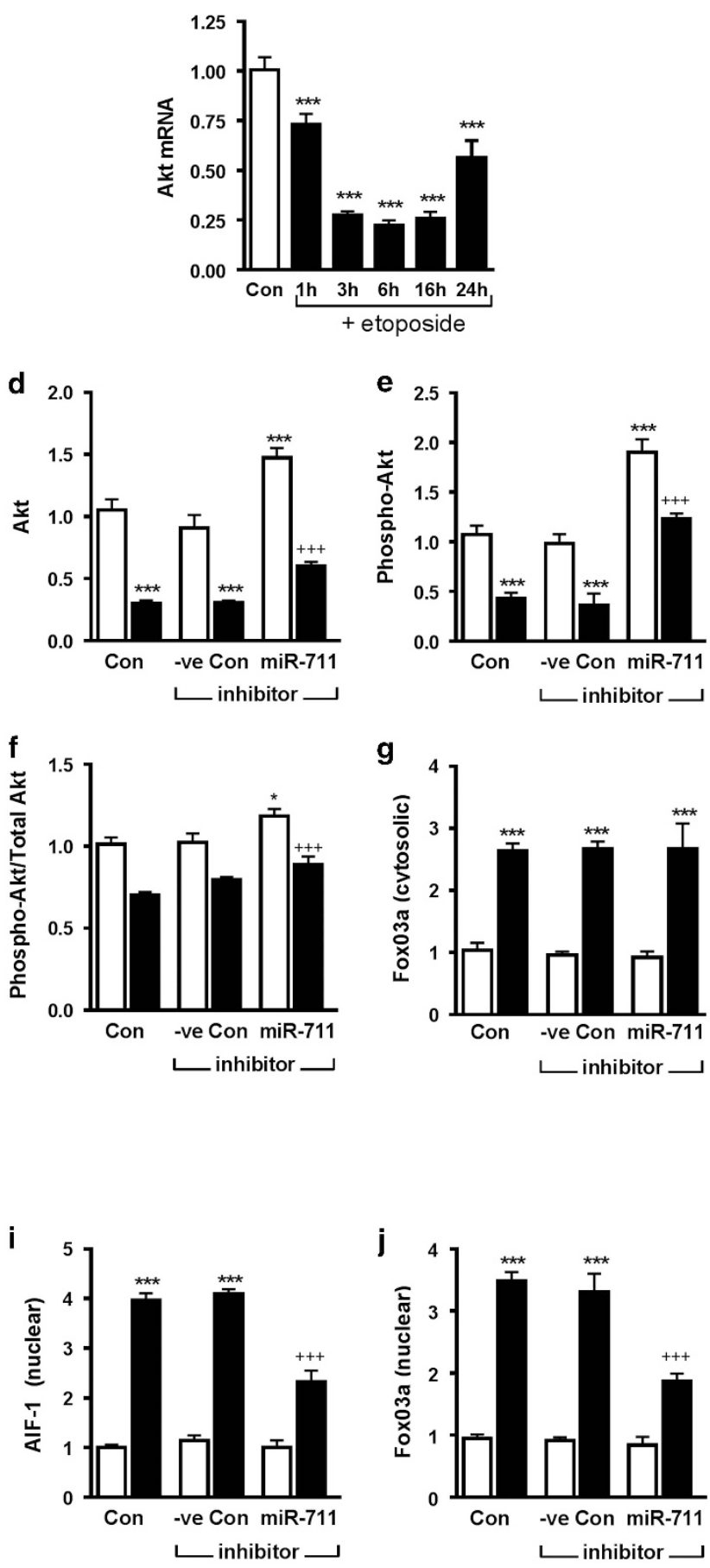
and Bim, as well as inhibiting downstream molecular mechanisms of neuronal apoptosis in the injured cortex. The latter included reduced mitochondrial release of cytochrome c (cytosol) and AIF-1 (cytosol and nuclear translocation) after TBI, and inhibition of $a$-fodrin cleavage. In addition, miR-711 hairpin inhibitor treatment reduced cortical lesion volume and neuronal cell loss in the cortex and hippocampus (CA2/3 and dentate gyrus), limiting cognitive functional deficits. The miR-711 inhibitor only modestly improved the motor function at a single intermediary time point. Whether optimization enhances this effect remains to be determined.

Reported changes in Akt levels after experimental TBI have been inconsistent. Two studies demonstrated rapidly decreased Akt levels, ${ }^{31,32}$ whereas another showed increased levels of total and phosphorylated Akt. ${ }^{33}$ Differences in injury type and tissue sampling may in part explain these varied results. Nonetheless, endogenous activation of Akt in specific areas (neurons) may represent a neuroprotective response to injury. ${ }^{34}$ Interventions targeting post-traumatic Akt inactivation can improve functional and histological outcomes after TBI. ${ }^{35}$ In contrast, Akt inhibition can exacerbate TBI neuropathology. ${ }^{36}$ Our study shows that Akt is downregulated at both mRNA and protein levels in the injured cortex after TBI. The reduction in Akt phosphorylation is proportional to the reduction in total $\mathrm{Akt}$, suggesting that changes in expression may have a preeminent role; this contrasts with the reported findings in another model, where phosphorylation appeared to be the primary factor. ${ }^{32}$ Inhibition of miR-711 partially restored the levels of total and phosphorylated/active Akt, as well as reducing FoxO3a translocation to the nucleus and Trib3 expression.

GSK3 $\beta$ has a pro-apoptotic role in several models of neuronal cell death: inhibition of GSK3 $\beta$ promotes neuronal survival, whereas overexpression causes neuronal apoptosis. ${ }^{15}$ Active GSK3 $\beta$ induces PUMA expression by modulating FoxO3a activity, and Akt-dependent phosphorylation on Ser9 is a key mechanism that inactivates GSK3 $\beta .^{15}$ Administration of miR-771 hairpin inhibitor increased the levels of phosphorylated/inactive GSK3 $\beta$ after TBI.

Changes in miR-711 have been reported after tissue injury or inflammation. Redell et al. ${ }^{3}$ suggested from miR arrays that miR-711 is rapidly upregulated in the hippocampus after brain trauma; however, quantitative PCR failed to confirm these findings and no functional analysis was performed. In microglia, changes in miR-711 may cause microglial activation. ${ }^{37}$ Outside of the CNS, other projected targets of miR-711 have been implicated in mediating its actions. These include HSP-70 and the transcription factor SP1, both of which are known to have neuroprotective effects. ${ }^{21,38-40}$ Future studies should therefore examine the relationship of miR-711 with changes in HSP-70, SP1 and microglial activation after TBI.

Although some differences in outcome have been reported following TBI in males and females, ${ }^{41}$ we used only male mice in this study to avoid the disrupting influence of reproductive cycle and hormone fluctuation.

Overall, our data demonstrate the importance of TBIinduced miR-711 upregulation in the induction of posttraumatic neuronal cell death, which may be in part mediated through its inhibition of Akt pathways. Consistent with this view of Akt as a key neuroprotective mechanism after CNS injury, others have shown that miR-21, which targets the Akt inhibitor PTEN, is neuroprotective after TBI. ${ }^{42,43}$ Although the upregulation of miR-711 occurs rapidly after TBI, it persists for several days suggesting that the therapeutic window for intervention may be significant.

\section{Materials and Methods}

Animals. Studies were performed using young adult ( 3 months old, $22-26 \mathrm{~g}$ ) male C57B//6 mice. All surgical procedures complied with the Guide for the Care and Use of Laboratory Animals published by NIH (DHEW publication NIH 85-23-2985).

Controlled cortical impact. $\mathrm{CCl}$ is an experimental model of $\mathrm{TBI}^{44}$ Our custom-designed $\mathrm{CCl}$ device ${ }^{45}$ consists of a microprocessor-controlled pneumatic impactor with a $3.5-\mathrm{mm}$ diameter tip. The 8-to 10-week-old C57BI/6 male mice were anesthetized with isoflurane evaporated in a gas mixture containing $70 \% \mathrm{~N}_{2} \mathrm{O}$ and $30 \% \mathrm{O}_{2}$ and administered through a nose mask (induction at $4 \%$ and maintenance at $2 \%$ ). Moderate-level injury was induced using an impactor velocity of $6 \mathrm{~m} / \mathrm{s}$ and deformation depth of $2 \mathrm{~mm}$ as previously described. ${ }^{46}$ After injury, the incision was closed, anesthesia terminated and the animal placed into a heated cage to maintain normal core temperature for $45 \mathrm{~min}$ post-injury. Sham-injured animals underwent anesthesia and surgical procedures but without cortical impact. In this study we only used male C57BI/6 mice to avoid the disrupting influence of reproductive cycle and hormone fluctuation in female mice on cell death mechanisms. References to TBI in regard to this work refers only to this $\mathrm{CCl}$ model.

In vivo drug treatments. At 15 min post-injury mice received a single i.c.v. injection of $0.5 \mathrm{nmol}$ of miR-711 hairpin inhibitor or negative control hairpin inhibitor. Drugs were administered in artificial cerebrospinal fluid, and injected into the left ventricle (coordinates from bregma $=\mathrm{A}:-0.5, \mathrm{~L}:-1.0$ and $\mathrm{V}:-2.0$ ) using a 30 -gauge needle attached to a Hamilton syringe at a rate of $0.5 \mathrm{ml} / \mathrm{min}$, with a final volume of $5 \mu \mathrm{l}$ of $0.1 \mathrm{mM}$ miR hairpin inhibitor.

Cell cultures. RCNs were derived from rat embryonic cortices as previously described. ${ }^{47}$ Neurons were maintained in serum-free conditions using the B27 supplement. Transfection of RCN was performed at 6 days in vitro. RCN were transfected with miR mimics and hairpin inhibitors using the Lipofectamine RNAiMAX Transfection Reagent (Invitrogen, Life Technologies, Carlsbad, CA, USA) according to the manufacturer's protocol. On the basis of preliminary titration experiments, we chose a final concentration of $50 \mathrm{nM}$ for the miR mimics, hairpin inhibitors and their negative controls. This concentration resulted in optimal transfection efficiency $(\sim 50 \%)$, was devoid of nonspecific changes in non-targeted miRs and had no neurotoxic effects. ${ }^{20}$ Moreover, the chosen concentration was

Figure 3 miR-711 hairpin inhibitor rescued Akt expression and attenuated translocation of AIF-1 and FoxO3a into nucleus. Controlled cortical impact in mice and etoposide treatment of cortical neurons decreased levels of Akt. qPCR quantification of Akt expression in the injured cortex of TBI mice (a) and in RCNs treated with etoposide as indicated (b). miR-711 hairpin inhibitor rescued Akt expression and attenuated translocation of AlF-1 and FoxO3a into nucleus. Neurons were transfected with miR-711 or negative control $(-\mathrm{ve}) \mathrm{miR}$ mimics and $4 \mathrm{~h}$ later treated with etoposide as described above. Twenty-four hours later whole cell lysates (c) and nuclear fractions (h) were fractioned on SDSpolyacrylamide gel, immunoblotted with antibodies against Akt, phosphorylated Akt, FoxO3a and $\beta$-actin in cytosolic fractions (c), and AlF-1, FoxO3a and histone H2A.X in nuclear fractions $(\mathbf{h})$. Protein levels in whole cell lysates $(\mathbf{d}-\mathbf{g})$ and nuclear fraction (i and $\mathbf{j})$ were quantified. Protein levels were quantified by densitometry, normalized to housekeeping protein and presented as fold change compared with control untreated levels. Data represent the mean \pm S.E.M. One-way ANOVA, SNK post hoc analysis; ${ }^{* * *} P<0.001$ versus mock untreated; ${ }^{++} P<0.01 ;{ }^{++} P<0.001$ versus etoposide-treated mock $(N=4)$. (h, bottom) Pooled nuclear fraction samples from each group and total lysates (total) were fractioned on SDS-polyacrylamide gel and immunoblotted with antibodies against porin and $\alpha$-tubulin 
associated with highest neuroprotective effects (data not shown). Four hours after transfection, media was replaced with normal condition media and cells treated with etoposide or staurosporine at a final concentration 50 and $0.5 \mu \mathrm{m}$, respectively. The following miR mimics and hairpin inhibitors were used: miRIDIAN microRNA Mimic Negative Control (-ve con mimic; CN-001000-01-05); miRIDIAN Mimic, Rat rnomiR-711 (C-320669-00-0005); miRIDIAN microRNA Hairpin Inhibitor Negative
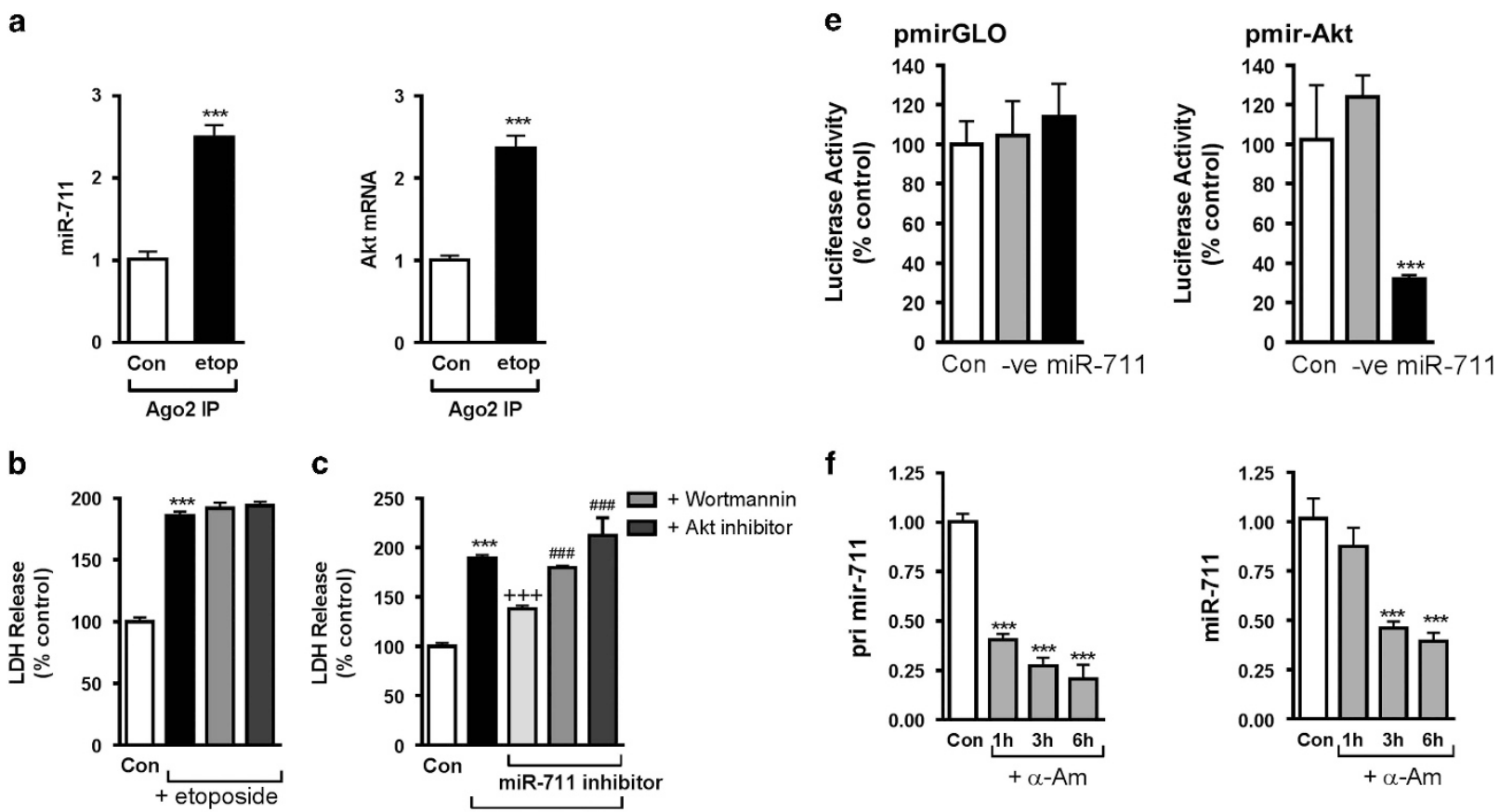

c
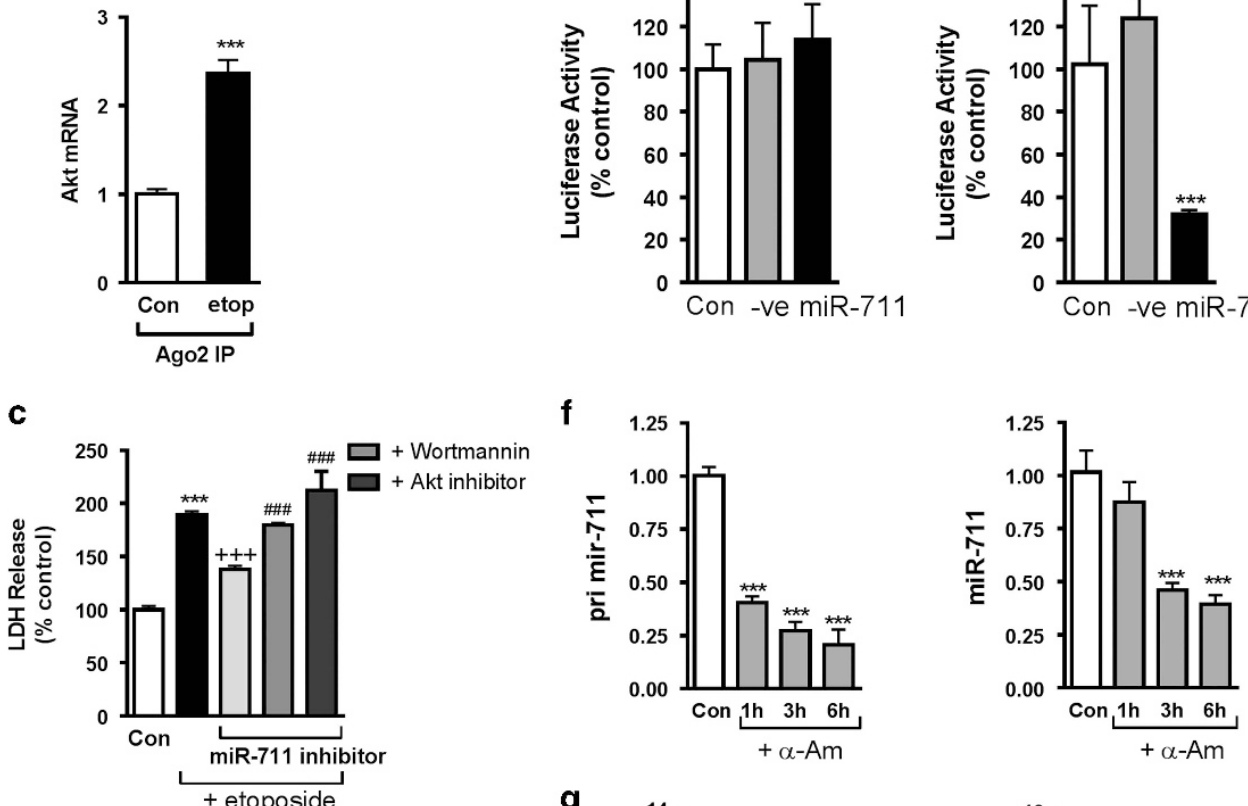

g
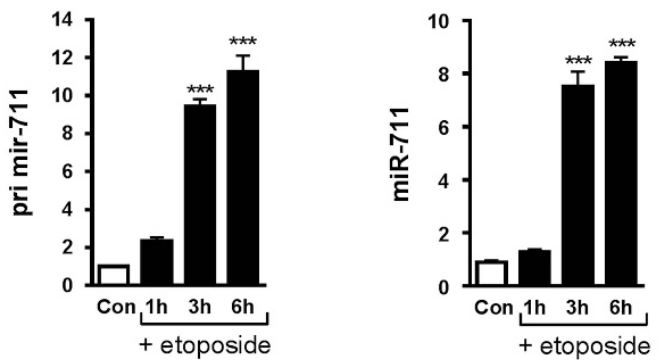

h
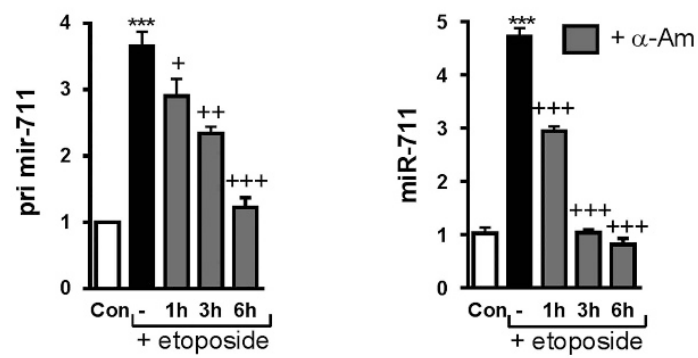

d
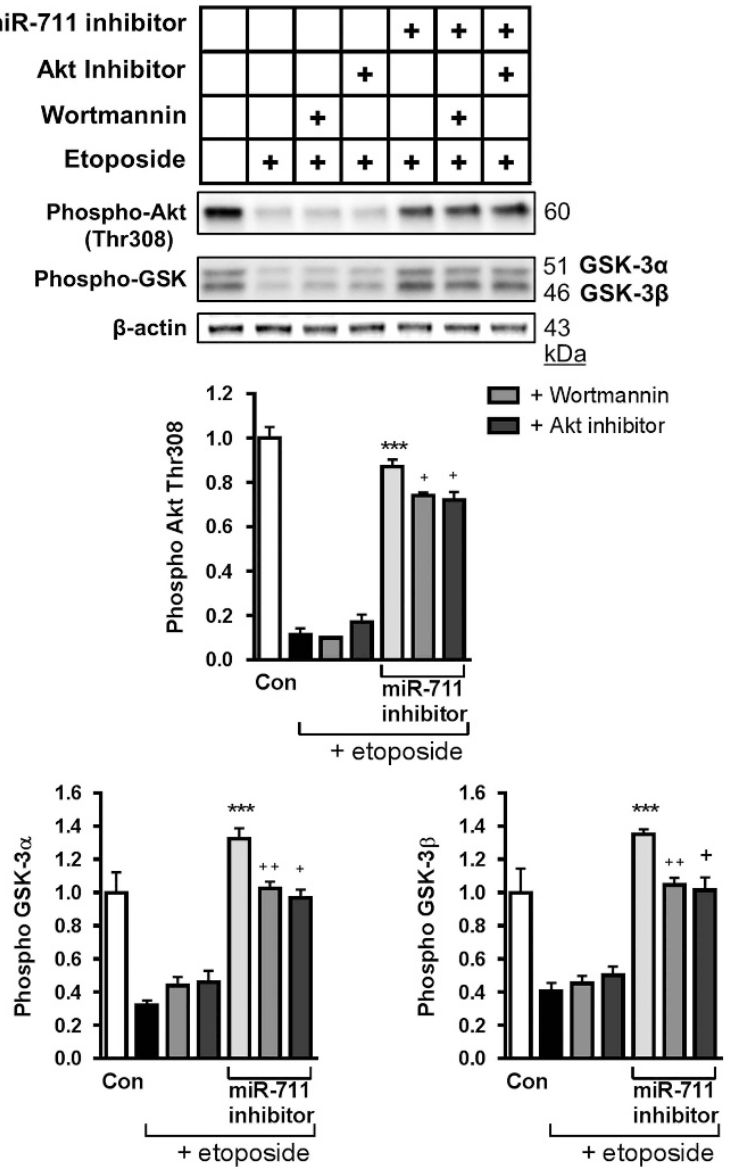
Control ( - ve con inhibit; IN-001005-01-05); miRIDIAN microRNA Rat rno-miR-711 Hairpin Inhibitor (IH-HMR-XX-0005) (Dharmacon Inc., Pittsburgh, PA, USA) Sequences of both miRIDIAN microRNA Mimic Negative Control and miRIDIAN microRNA Hairpin Inhibitor Negative Control are based on Caenorhabditis elegans microRNAs and have minimal sequence identity in human, mouse and rat. In some experiments downstream signaling pathways were targeted using the following inhibitors: Akt inhibitor (1L6-hydroxymethyl-chiro-inositol-2-(R)-2-0-methyl-3-0-octadecyl-sn-glycerocarbonate; Calbiochem, Billerica, MA, USA) selectively inhibits Akt $\left(\mathrm{PKB}\right.$; IC $\mathrm{C}_{50}$ of $\left.5.0 \mu \mathrm{M}\right)$ and moderately inhibits PI3-K activity $\left(\mathrm{IC}_{50}=83.0 \mu \mathrm{M}\right)$, and Wortmannin (Cell Signaling Technology, Inc., Danvers, MA, USA), which inhibits PI3 kinase. RCNs were treated with Akt inhibitor or Wortmannin at final concentration $6.25 \mu \mathrm{M}$ and $25 \mathrm{nM}$, respectively.

Cell death, cell viability and in-plate fluorometric caspase-3 assays. Cell death, cell viability and in-plate fluorometric caspase-3 activity were measured using the LDH, Calcein AM and DEVD-AMC assays, respectively, as previously described. ${ }^{48}$ Each individual treatment/time point reflects six replicates for all assays performed in RCNs cultured in 96-well plates.

RNA-interacting protein immunoprecipitation using AGO2specific antibodies. Ago2 immunoprecipitation was performed as previously described. ${ }^{49}$ Briefly, RCNs were suspended in $500 \mu$ l of lysis buffer $(150 \mathrm{mM} \mathrm{KCl}$, $25 \mathrm{mM}$ Tris- $\mathrm{HCl}(\mathrm{pH} 7.4), 5 \mathrm{mM}$ EDTA, 0.5\% NP-40, $5 \mathrm{mM}$ DTT, and protease inhibitor and phosphatase inhibitor $(2,3)$ cocktails (Sigma-Aldrich, St. Louis, MO, USA) at $4{ }^{\circ} \mathrm{C}$ for $20 \mathrm{~min}$ and the cell lysates were separated by centrifugation at $12,000 \times \mathrm{g}$ for $20 \mathrm{~min}$ at $4^{\circ} \mathrm{C}$. A volume of $50 \mu \mathrm{l}$ of protein A/G UltraLink Resin (Thermo Scientific, Waltham, MA, USA) and $20 \mu$ lof Argonaute 2 (Ago2) antibody (Cell Signaling, Danvers, MA, USA) were added to $400 \mu$ l of cell lysate (in a final $1 \mathrm{ml}$ mixture filled with lysis buffer) and the mixture was rotated for $4 \mathrm{~h}$ at $4{ }^{\circ} \mathrm{C}$. The beads were washed three times with $1 \mathrm{ml}$ lysis buffer to remove nonspecific binding. RNAs bound on the beads were extracted by miRNeasy Kit (Qiagen, Valencia, CA, USA). miR and gene expression was analyzed by qPCR (as described below).

Construction of reporter plasmids and luciferase assays. To produce reporter plasmids containing 3 '-UTRs of mouse Akt sequences were PCR amplified, digested, gel purified, ligated and cloned into pmirGLO vector (Promega, Madison, WI, USA) digested with Xbal and Sall restriction enzymes. The following primers were used to amplify $3^{\prime}$-UTR of mouse Akt; $3^{\prime}$-UTR forward primer $5^{\prime}$-tg TCTAGACCACGCTCCTCTGCATT-3', reverse primer $5^{\prime}$-tgGTCGACGCTCTCC TGTCACCAAGATT- $3^{\prime}$. Xbal site was added on $5^{\prime}$ end of forward primers, and Sall site was added to $5^{\prime}$ end of reverse primers for cloning into pmirGLO vector Xbal, Sall-digested vector (Xbal and Sall sites are marked bold). RCNs was cultured in 96-well plates and transfected as described above. All assays were performed at $24 \mathrm{~h}$ after transfection with the dual luciferase assay (Promega) on
BioTek Synergy Ht Microplate Reader (BioTek, Winooski, VT, USA). Firefly luciferase activity was normalized to Renilla luciferase activity. Experiments were performed in triplicate.

RNA isolation. Total RNA was isolated using miRNeasy Kit (Qiagen). During the process of isolation, samples were treated with RNase-free DNase (Qiagen) to digest DNA contamination of the samples according to the manufacturer's protocol.

miRNA arrays and data analysis. A unit of $100 \mathrm{ng}$ of total RNA was used for miRs' expression profiling using Affymetrix GeneChip miRNA 2.0 Arrays (Affymetrix, Santa Clara, CA, USA). Briefly, total RNA from cells was extracted as described above. Double-stranded CDNA was prepared from RNA and used as the template for in vitro transcription to prepare biotinylated cRNA. The target was fragmented and hybridized to probes using standard Affymetrix protocols. Expression values were computed using normalization function $\mathrm{RMA}^{50}$ from Bioconductor's affy ${ }^{51}$ package. Only values annotated as mouse probes (Mmu) were further considered. Expression values for the data set were fitted to a linear model in order to determine differentially expressed miRNAs between different time points. Comparisons were made between the naive control group (time $0 \mathrm{~h}$ ) and each of the TBI groups (1, 6, 24 and $72 \mathrm{~h}$ post-injury; $n=3$ arrays per group/time). Those miRNAs showing an adjusted $P$-value (false discovery rate lower than 0.05 ) for any of these comparisons were determined to be differentially expressed and selected for further analysis.

qPCR. Verso cDNA Kit (Thermo Scientific) was used to synthesize cDNA from purified total RNA as described previously. ${ }^{20}$ Quantitative real-time PCR amplification was performed by using cDNA TaqMan Universal Master Mix II (Applied Biosystems, Grand Island, NY, USA). TaqMan Gene Expression assays for following mouse genes were performed: GAPDH (Mm99999915_g1) and Trib3 (Mm00454879_m1) (Applied Biosystems). Reactions were amplified and quantified using a $7900 \mathrm{HT}$ Fast Real-Time PCR System and the corresponding software (Applied Biosystems). Gene expression was normalized to GAPDH, and the relative quantity of mRNAs was calculated based on the comparative $\mathrm{Ct}$ method. $^{52}$

miR reverse transcription. Quantitative real-time $P C R$ was used to measure the expression of primary miRNA-711 (pri-mir-711) and mature miR-711. A unit of $10 \mathrm{ng}$ of total RNA was reverse transcribed using TagMan miRNA Reverse Transcription Kit (Applied Biosystems) with miRNA-specific primers. Reverse transcription reaction products $(1.5 \mu \mathrm{l})$ were used for qPCR as described above. TaqMan Gene Expression assays for following miRs were used: mmu-miR-711 (001646); rno-miR-711 (241136_mat); rno-mir-711 (Rn04229705_pri); U6 snRNA (001973) and snoRNA202 (001232) (Applied Biosystems).

Figure 4 Etoposide treatment increased the levels of miR-711 and Akt within the RISC. (a) Etoposide treatment increased the levels of miR-711 and Akt within the RISC. Neurons were collected $6 \mathrm{~h}$ after etoposide treatment, subjected to RIP with Ago2 antibodies and samples used for qPCR analysis. qPCR quantification of miR-711 and Akt levels in precipitates after RIP. Data represent the mean \pm S.E.M. Student's $t$-test; ${ }^{* \star *} P<0.001$ versus mock untreated RCN. (b) There was no significant increase of neuronal cell death in cells treated with etoposide in combination with Akt inhibitor or Wortmannin compared with etoposide-treated cells. Neurons were treated with etoposide in the presence/ absence of Akt inhibitors (Wortmannin, Akt inhibitor). Twenty-four hours later LDH release was measured. Data are expressed as percentage of control untreated neurons (mean \pm S.E.M.). One-way ANOVA, SNK post hoc analysis; ${ }^{* \star} P<0.001$ versus mock untreated RCN. (c) Inhibitors of Akt phosphorylation blocked the neuroprotective effects of miR-711 hairpin inhibitor. Neurons were transfected with miR-711 hairpin inhibitors and $4 \mathrm{~h}$ later treated with etoposide in the presence/absence of Akt inhibitors. Twenty-four hours later LDH release was measured. Data are expressed as percentage of control untreated neurons (mean \pm S.E.M.). One-way ANOVA, SNK post hoc analysis; ${ }^{* \star *} P<0.001$ versus mock untreated RCN; ${ }^{++} P<0.01$ versus etoposide-treated cells; ${ }^{\# \# \#} P<0.001$ versus miR-711 hairpin inhibitor-transfected and etoposide-treated cells $(N=6)$. (d) RCNs were transfected and treated as described in $\mathbf{c}$. Twenty-four hours later whole cell lysates were fractioned on SDS-polyacrylamide gel and immunoblotted with antibodies against Akt, phosphorylated Akt, GSK3 and $\beta$-actin. Protein levels were quantified by densitometry, normalized to housekeeping protein, and presented as fold change compared with control untreated levels. Data represent the mean \pm S.E.M. One-way ANOVA, SNK post hoc analysis; ${ }^{* \star} P<0.001$ versus etoposide-treated cells; ${ }^{+} P<0.05,{ }^{++} P<0.01$ versus miR-711 hairpin inhibitor-transfected and etoposide-treated cells $(N=4)$. (e) miR-711 targets $3^{\prime}$-UTRs of Akt mRNA. RCNs were transfected with either control vector (pmirGLO) or pmir-AKT reporter plasmids and co-transfected with either negative control miR ( - ve) or miR-711 mimic. Luciferase activity was analyzed $24 \mathrm{~h}$ after transfection. Normalized luciferase activities were shown as the percentage relative to the cells transfected with plasmid alone, which was set as $100 \%$. Experiments were performed in triplicate. One-way ANOVA, SNK post hoc analysis; ${ }^{* \star *} P<0.001$ versus RCN co-transfected with pmir-Akt reporter plasmid and negative control miR $(-v e)$ mimic $(N=3)$. Analysis by one-way ANOVA followed by multiple pairwise comparisons using SNK post hoc test. (f) miR-711 is rapidly regulated at transcription stage following etoposide-induced neuronal cell death. Neurons were treated with $\alpha$-amanitin $(\alpha-\mathrm{Am})$ to final concentration $10 \mu \mathrm{g} / \mathrm{ml}$, and levels of pri-mir-711 and miR-711 were measured at 1,3 and $6 \mathrm{~h}$ time points by qPCR. One-way ANOVA, SNK post hoc analysis; ${ }^{* *} P<0.001$ versus mock untreated RCN. (g) Neurons were treated with etoposide and levels of pri-mir-711 and miR-711 were analyzed at 1,3 and $6 \mathrm{~h}$ time points by qPCR. One-way ANOVA, SNK post hoc analysis; ${ }^{* \star *} P<0.001$ versus mock untreated RCN $(N=6)$. (h) Neurons were treated with etoposide for $2 \mathrm{~h}$ followed by $\alpha$-Am treatment to final concentration $10 \mu \mathrm{g} / \mathrm{ml}$. Levels of pri-mir-711 and miR-711 were measured at 1,3 and $6 \mathrm{~h}$ after $\alpha$-Am treatment. One-way ANOVA, SNK post hoc analysis; ${ }^{* \star \star} P<0.001$ versus mock untreated $\mathrm{RCN} ;{ }^{+} P<0.05,{ }^{++} P<0.01,{ }^{++} P<0.001$ versus etoposide-treated cells $(N=6)$ 

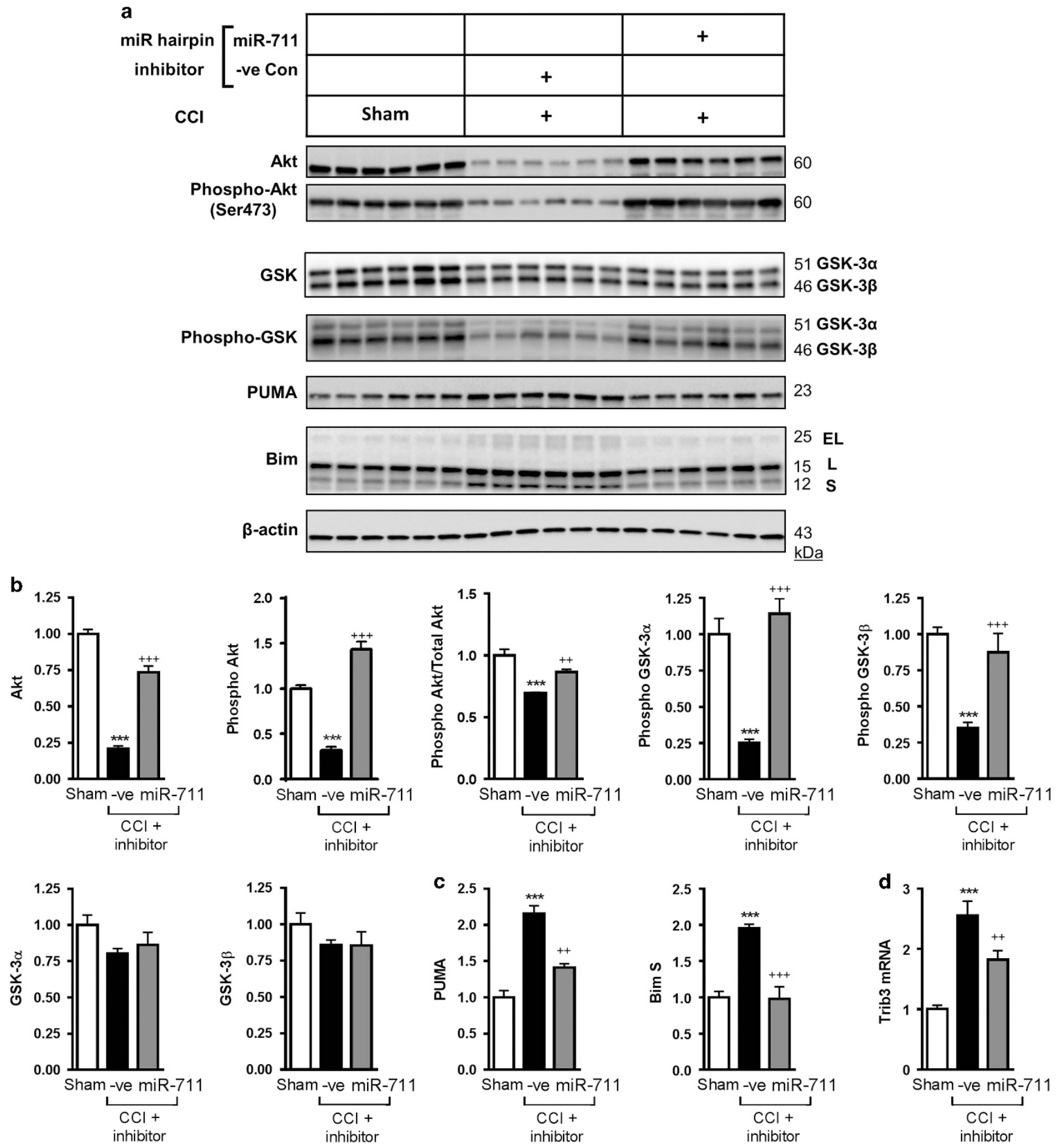

Figure 5 Central administration of miR-711 hairpin inhibitor increased levels of Akt in the injured cortex after TBI. (a) Whole tissue lysates from mouse cortex $24 \mathrm{~h}$ after sham or TBI and i.c.v. administration of miR-711 or - ve Con hairpin inhibitors were fractioned on SDS-polyacrylamide gel and immunobloted with antibodies against Akt, phosphorylated Akt, GSK3 $\alpha / \beta$, phosphorylated GSK3, PUMA, Bim (Bim small (S) (12 kDa) and Bim large (L) (15 kDa) (Bim extra-large isoform (EL) ( $25 \mathrm{kDa})$ was very weakly detected and $\beta$-actin. (b) Protein levels of Akt, phosphorylated Akt, GSK3 $\alpha / \beta$, phosphorylated GSK3 $\alpha / \beta$ were quantified by densitometry, normalized to $\beta$-actin and presented as fold change compared with sham-injured controls. Levels of phosphorylated Akt and phosphorylated GSK3 $\alpha / \beta$ were also normalized to Akt and GSK3 $\alpha / \beta$, respectively. (c) Protein levels of Puma and Bim S were quantified by densitometry, normalized to $\beta$-actin and presented as fold change compared with sham-injured controls. Data represent the mean \pm S.E.M. One-way ANOVA. SNC post hoc test, ${ }^{* \star \star} P<0.001$ versus sham; ${ }^{++} P<0.01 ;{ }^{++} P<0.001$ versus -ve Con miR inhibitor $\mathrm{CCl}$ group (N=6). (d) $q P C R$ quantification of Trib3 mRNA in mouse cortex $24 \mathrm{~h}$ after sham or TBI mice that received i.c.v. administration of miR-711 or - ve Con hairpin inhibitors. Data represent the mean \pm S.E.M. One-way ANOVA, SNC post hoc test; ${ }^{* \star}{ }^{*} P<0.001$ versus sham; ${ }^{++} P<0.01$ versus - ve Con miR inhibitor $\mathrm{CCl}$ group $(N=4)$ 
a

\begin{tabular}{c}
$\begin{array}{c}\text { miR hairpin } \\
\text { inhibitor }\end{array}$ \\
\cline { 2 - 4 } $\operatorname{CCl}$
\end{tabular}

AIF-1
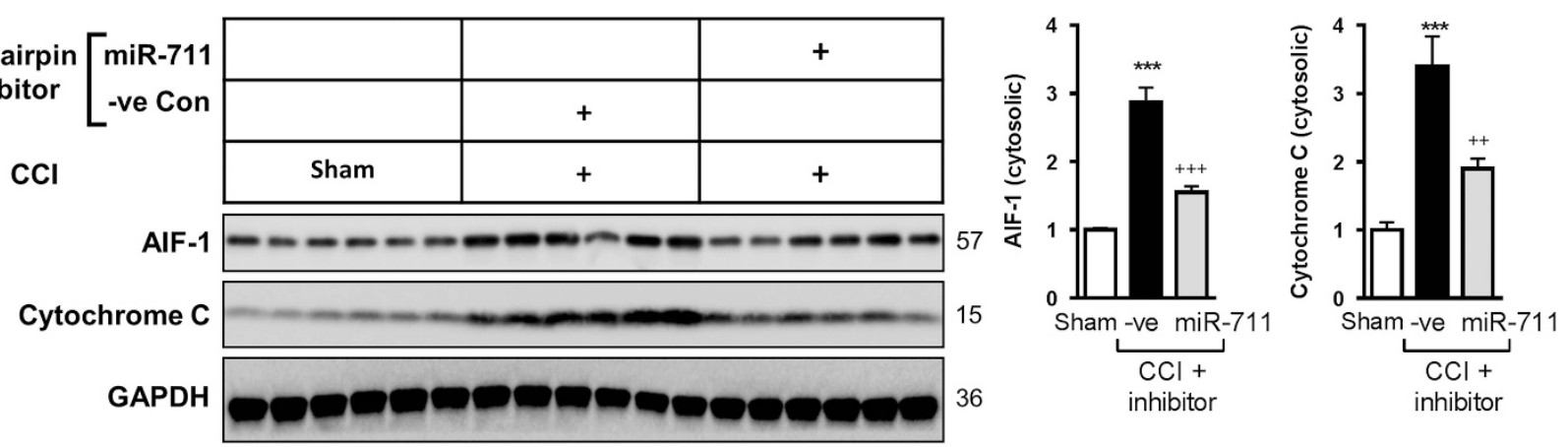

b

Nuclear fraction
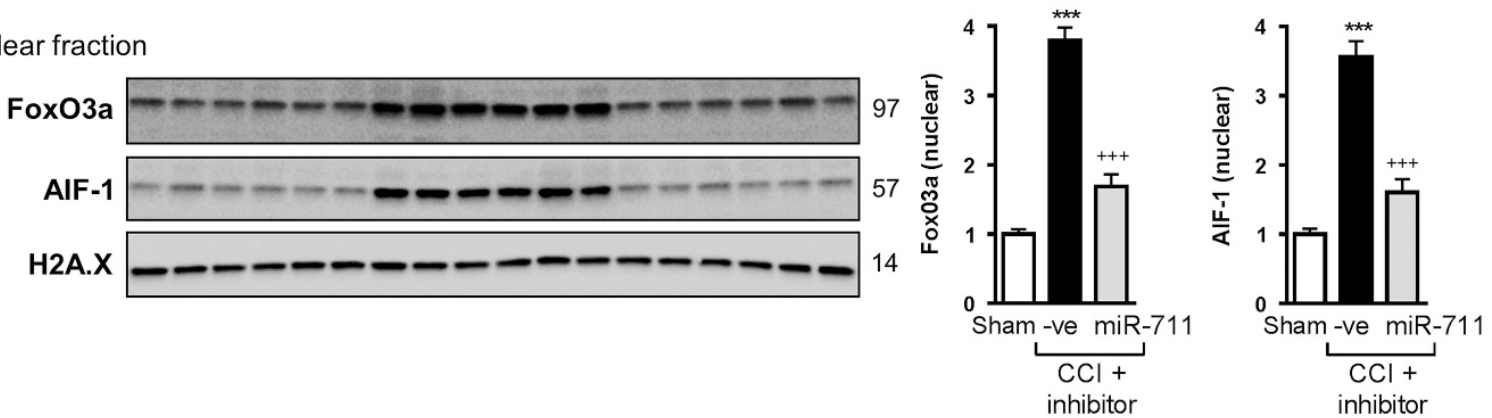

C
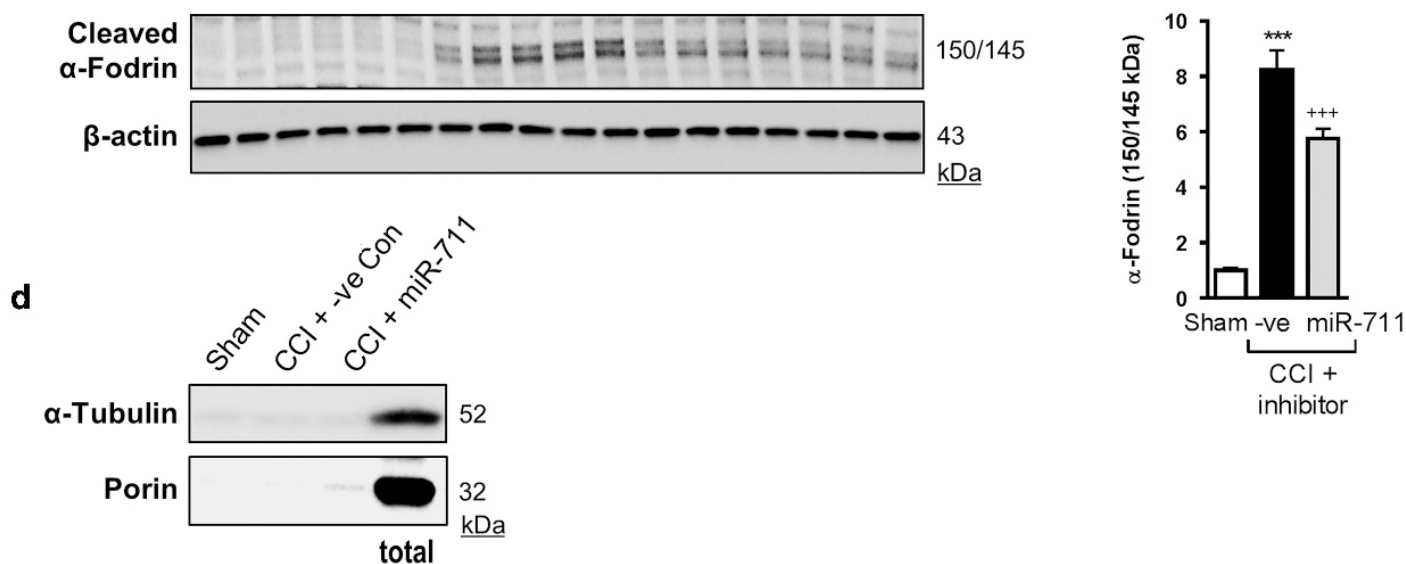

Figure 6 Central administration of miR-711 hairpin inhibitor attenuated molecular mechanisms of neuronal apoptosis after TBI. (a) Cytosolic fractions from mouse cortex $24 \mathrm{~h}$ after sham or TBI and i.c.v. administration of miR-711 or - ve Con hairpin inhibitors were fractioned on SDS-polyacrylamide gel and immunobloted with antibodies against AIF-1 and cytochrome C. (b) Nuclear fractions were run on SDS-polyacrylamide gel and immunobloted with antibodies against FoxO3a and AIF-1. Whole cell lysates were run on SDSpolyacrylamide gel and immunobloted with antibodies against $\alpha$-fodrin (c). Protein levels were quantified by densitometry, normalized to housekeeping proteins and presented as fold change compared with sham-injured controls. Data represent the mean \pm S.E.M. One-way ANOVA, SNC post hoc test; ${ }^{* *} P<0.001$ versus sham; ${ }^{++} P<0.01 ;{ }^{+++} P<0.001$ versus - ve Con miR inhibitor CCI group $(N=6)$. (d) Pool of nuclear fraction samples from mouse cortex $24 \mathrm{~h}$ after sham, or $\mathrm{CCl}$ in mice that were administered miR-711 (miR-711) or - ve Con ( - ve Con) hairpin inhibitors by i.c.v. administration and total tissue lysates (total) were fractioned on SDS-polyacrylamide gel and immunobloted with antibodies against porin and $\alpha$-tubulin

Cell lysates preparation and western blot. Whole-cell extracts and western blot were prepared/performed as previously described. ${ }^{53}$ Chemiluminescence was captured on a Kodak Image Station 4000R station (Carestream Health, Rochester, NY, USA), and protein bands were quantified by densitometric analysis using Carestream Molecular Imaging Software. The data presented reflect the intensity of the target protein band compared with the control and were normalized based on the intensity of the endogenous control for each sample (expressed in arbitrary units).

Antibodies. The following antibodies were used in this study. Histone H2A.X (ab11175; Abcam); AIF (sc-13116), Apaf-1 (sc-65890), cytochrome c (sc-13560) and Bim (sc-11425; Santa Cruz Biotechnology, Dallas, TX, USA); Cleaved
Caspase-3 (\#9661), Cleaved PARP (\#9545); Phospho-GSK3 $\alpha / \beta$ (Ser21/9) (\#9331), Fox03a (75D8) (\#2497), Akt (pan) (11E7) (\#4685), Phospho-Akt (Ser473) (\#4060), $\alpha$-tubulin (11H10), porin (D73D12) and GSK3 $\alpha / \beta$ (D75D3; Cell Signaling Technology, Inc.); GAPDH (ADI-CSA-335) and $\alpha$-fodrin (BML-FG6090; Enzo Life Sciences, Inc.); PUMA (\#3041; ProSci Incorporated, Poway, CA, USA); and $\beta$-actin (A1978; Sigma).

Subcellular fractionation. Subcellular fractionation was performed as described ${ }^{53}$ with some modifications. RCN were harvested and washed in icecold phosphate-buffered saline. Cell suspension was centrifuged at $500 \mathrm{~g}$ for $15 \mathrm{~min}$ at $4^{\circ} \mathrm{C}$. Cell pellet was resuspended for $10 \mathrm{~min}$ on ice in the digitonin lysis buffer (20 mM HEPES, pH 7.4, 80 mM KCl, 1 mM EDTA, 1 mM EGTA, 1 mM DTT, 250 mM 
a

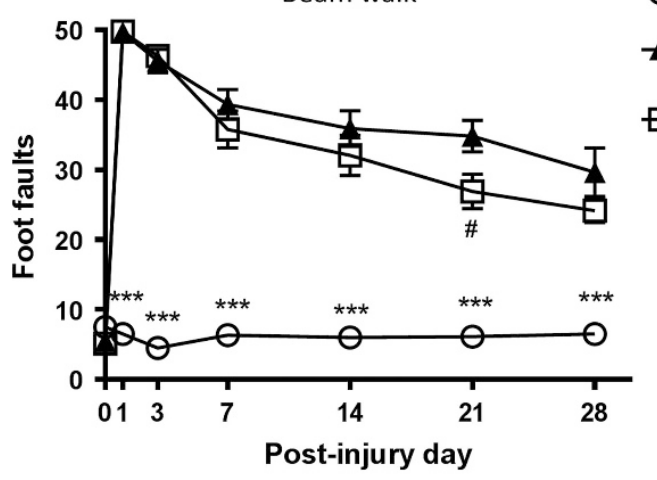

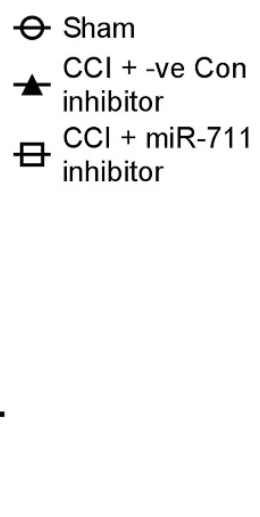

b

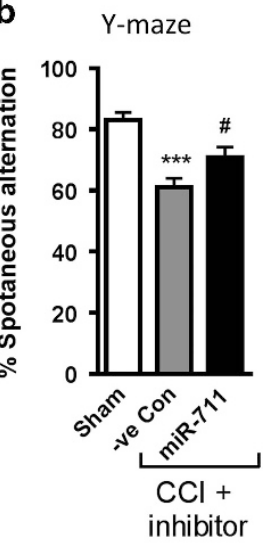

c Novel object recognition
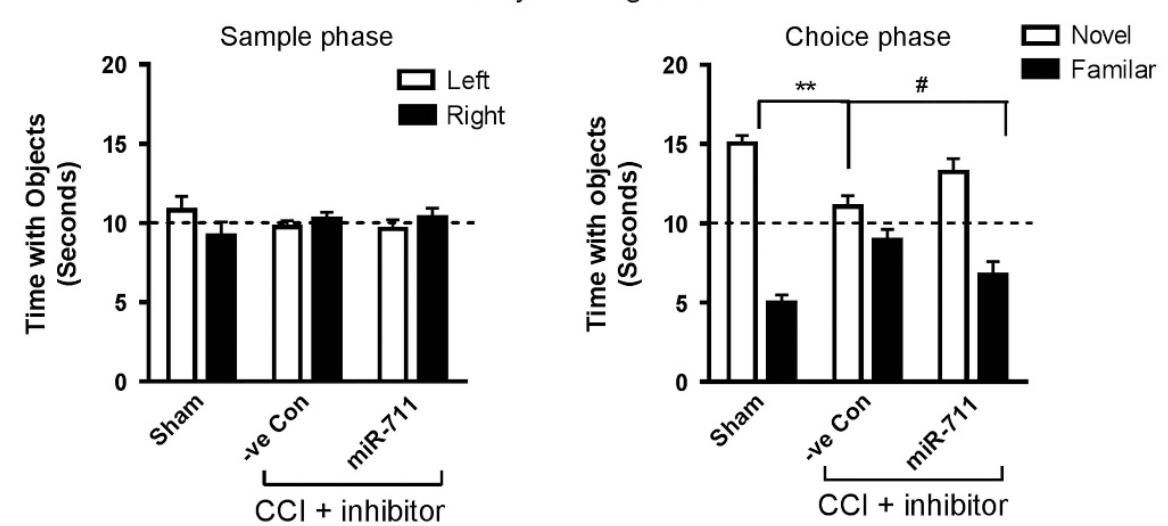

Figure 7 miR-711 hairpin inhibitor treatment attenuated TBI-induced deficits in motor and cognitive functions. (a) Central administration of miR-711 hairpin inhibitor improves motor function in beam walk test. All mice had $<10$ foot faults before CCI. Compared with sham-injured mice TBI induced significant deficits in fine motor coordination and there was a aignificant differences between the - ve Con miR inhibitor $\mathrm{CCl}$ and sham group at each time point $\left({ }^{* \star *} P<0.001\right)$. There was a significant difference between miR-711 hairpin inhibitor $\mathrm{CCl}$ group and the - ve Con miR inhibitor CCI group at 21 days post-injury $\left({ }^{\#} P<0.05\right)$. Repeated measures one-way ANOVA, SNK post hoctest. Mean \pm S.E.M. $(N=6-12)$. (b) Central administration of miR-711 hairpin inhibitor improves spatial memory using the Y-maze spontaneous alternation test. Sham-injured mice showed intact spatial working memory function because they all performed significantly better than the $50 \%$ chance level $(N=6)$. The - ve Con miR inhibitor $C C l$ group $\left({ }^{* \star \star} P<0.001 ; N=11\right)$ showed significantly reduced percentages of spontaneous alternation, whereas the miR-711 hairpin inhibitor $\mathrm{CCl}$ group $(\# P<0.05 ; N=12)$ had a significantly increased percentage of spontaneous alternation compared with the - ve Con miR inhibitor CCI group. One-way ANOVA, SNK post hoc test. (c) Central administration of miR-711 hairpin inhibitor improves retention memory using the novel object recognition test. All groups spent equal time with the two identical objects during the sample phase on day 22 postinjury (dashed line at $10 \mathrm{~s}$ ). Twenty-four hours after the sample phase, the time spent with the novel and familiar objects during the choice phase was recorded. The miR-711 hairpin inhibitor $\mathrm{CCl}$ group spent significantly more time with the novel object when compared with the - ve Con miR inhibitor CCl group $(\# P<0.05)$. Significant differences were also observed between the sham and - ve Con miR inhibitor CCI group $\left({ }^{*} P<0.01\right)$. One-way ANOVA, SNC post hoc test, $N=6-12$

sucrose, $200 \mu \mathrm{g} / \mathrm{ml}$ digitonin and protease inhibitor and phosphatase inhibitor $(2,3)$ cocktails (Sigma-Aldrich). The lysate was centrifuged at $1000 \times g$ for 5 min at $4^{\circ} \mathrm{C}$ to pellet the nuclei. The supernatant was transferred to a new tube and centrifuged again at $12000 \times \mathrm{g}$ for $10 \mathrm{~min}$ at $4^{\circ} \mathrm{C}$ to pellet the mitochondria. The resulting supernatant, representing the cytosolic fraction, was recovered. Nuclear and mitochondrial lysates were prepared in RIPA buffer (Teknova, Hollister, CA, USA) with Protease Inhibitor Cocktail (Sigma-Aldrich). Tissue samples were homogenized in glass dounce following 20 passes with a $20-G$ needle. All steps were performed on ice. To check the purity of nuclear fractions we probed our extracts $(20 \mu \mathrm{g}$ of protein per well) with antibodies against the well-established mitochondrial marker porin $^{54}$ (Engel et al. PMID: 20646170) and cytosolic marker $\alpha$-tubulin ${ }^{55}$ (Landshamer et al. PMID: 18535584; Figures 3h and 6d).

Beam walk test. Chronic motor function was evaluated using a beam walking task ${ }^{45}$ a method that is particularly good at discriminating fine motor coordination deficits. The test was performed at 0 (immediately before CCI), 1, 3, 7, 14 and 28 days after injury.
Novel object recognition test. Novel object recognition (NOR) was used to evaluate non-spatial hippocampal-mediated memory on days 22 and 23 post-injury as previously described. ${ }^{56}$

Y-maze spontaneous alternation test. The Y-maze measures the willingness of rodents to explore new environments and assesses spatial working memory. Rodents typically prefer to investigate a new arm of the maze rather than returning to one that was visited previously. The Y-maze test was performed on day 14 post-injury as previously described. ${ }^{35}$

Lesion volume assessment. Sections were stained with cresyl violet (FD NeuroTechnologies, Columbia, MD, USA), dehydrated and mounted for analysis. Lesion volume was quantified based on the Cavalieri method ${ }^{57}$ of unbiased stereology using Stereologer 2000 program software (Systems Planning and Analysis, Alexandria, VA, USA). The lesion volume was quantified by outlining the missing tissue on the injured hemisphere using the Cavalieri estimator with a grid spacing of $0.1 \mathrm{~mm}$. From 96 total $60-\mu \mathrm{m}$ sections, every eighth section was analyzed beginning from a random start point. 
a

a -ve Control
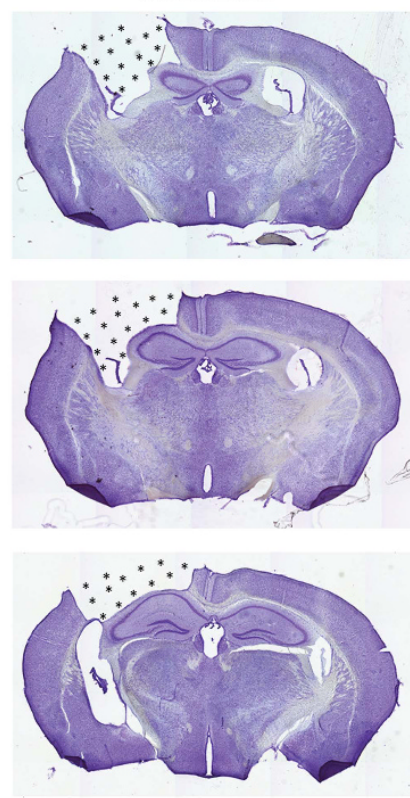

miR-711 inhibitor
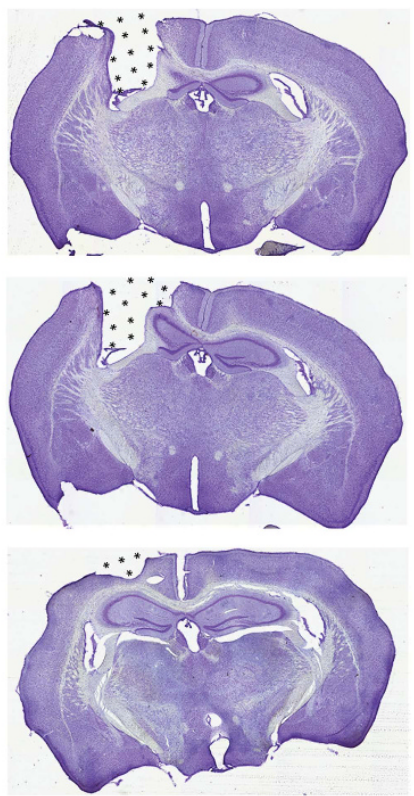

b

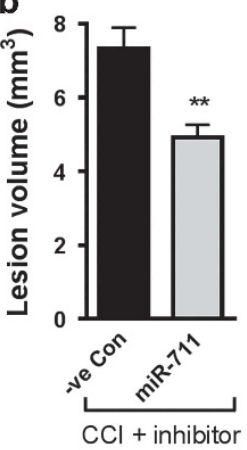

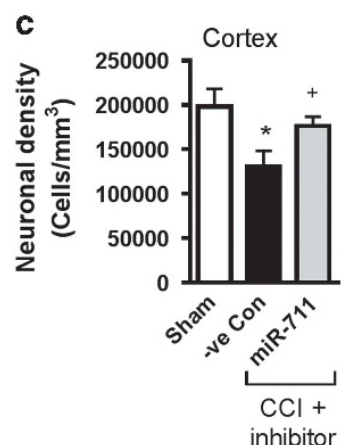
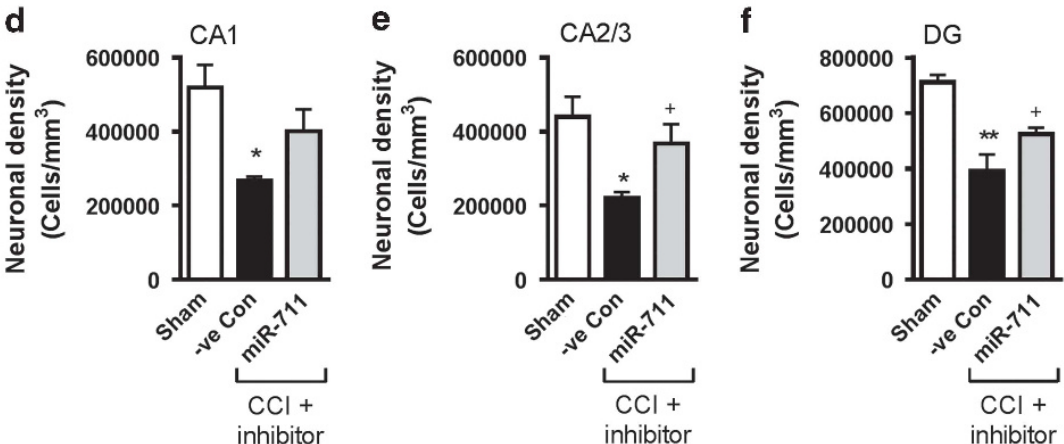

Figure 8 miR-711 hairpin inhibitor treatment reduced lesion volume and neuronal loss in the cortex and hippocampus after TBI. Stereological assessment of lesion volume at 28 days post-injury. (a) Representative images from each group are shown. Lesion cavities are marked by asterisks. (b) There was a significant reduction in lesion volume in miR-711 hairpin inhibitor $\mathrm{CCl}$ group when compared with the - ve $\mathrm{Con}$ miR inhibitor $\mathrm{CCl}$ group $\left({ }^{* \star} P<0.01\right)$. Student's $t$-test, $N=6$. Stereological assessment of neurons in the cortex (c), CA1 (d), CA2/3 (e) and DG (f) subregions of hippocampus. There were significant differences in neuronal densities between sham-injured and - ve Con miR inhibitor $\mathrm{CCl}$ groups $\left({ }^{*} P<0.05,{ }^{* *} P<0.01\right)$. Treatment with miR-711 hairpin inhibitor significantly increased neuronal densities in the cortex $\left({ }^{+} P<0.05\right), \mathrm{CA} 2 / 3\left({ }^{+} P<0.05\right)$ and $\mathrm{DG}$ $\left({ }^{+} P<0.01\right)$ compared with - ve Con miR inhibitor $\mathrm{CCl}$ group. One-way ANOVA, SNC post hoc test, $N=3-6$

Assessment of neuronal cell loss. Stereo investigator software (MBF Biosciences, Williston, VT, USA) was used to count the total number of surviving neurons in the cortex and Cornu Ammonis (CA)1, CA2, CA3, and dentate gyrus (DG) subregions of the hippocampus using the optical fractionator method of unbiased stereology as described. ${ }^{57}$ Every fourth $60-\mu \mathrm{m}$ section between -1.22 and $-2.54 \mathrm{~mm}$ from bregma was analyzed, beginning from a random start point. The optical dissector had a size of $50 \mu \mathrm{m}$ by $50 \mu \mathrm{m}$ in the $x$ and $y$ axes, respectively, with a height of $10 \mu \mathrm{m}$ and a guard-zone of $4 \mu \mathrm{m}$ from the top of the section. The sampled region for each subfield was demarcated in the injured hemisphere and cresyl violet neuronal cell bodies were counted. For the cortex a grid spacing of $400 \mu \mathrm{m}$ in the $x$ axis and $400 \mu \mathrm{m}$ in the $y$ axis was used, resulting in an area fraction of 164th. For the CA1, CA2 and CA3 subregions a grid spacing of $75 \mu \mathrm{m}$ in the $x$ axis and $100 \mu \mathrm{m}$ in the $y$ axis was used, resulting in an area fraction of one-twelfth. For the DG subregion, a grid spacing of $175 \mu \mathrm{m}$ in the $x$ axis and $100 \mu \mathrm{m}$ in the $y$ axis was used, resulting in an area fraction of one-twenty-eighth. The volume of each subfield was measured using the Cavalieri estimator method with a grid spacing of $50 \mu \mathrm{m}$. The estimated number of surviving neurons in each field was divided by the volume of the region of interest to obtain the neuronal cellular density, expressed as counts per $\mathrm{mm}^{3}$.
Statistical analysis. Analysis was performed using the Prism version 6 for Windows (GraphPad Software, La Jolla, CA, USA) as indicated. If the data passed a normality test, further analysis involved one-way ANOVA followed by multiple pairwise comparisons using the Student-Newman-Keuls post hoc test.

\section{Conflict of Interest}

The authors declare no conflict of interest.

Acknowledgements. This work was supported by grants R01 NS061839 to AIF and R01 NR012686 to SGD. We thank Taryn Aubrecht and Xiaoyi Lin for technical assistance.

1. Griffiths-Jones S, Grocock RJ, van Dongen S, Bateman A, Enright AJ. miRBase: microRNA sequences, targets and gene nomenclature. Nucleic Acids Res 2006; 34: D140-D144.

2. Ziu M, Fletcher L, Rana S, Jimenez DF, Digicaylioglu M. Temporal differences in microRNA expression patterns in astrocytes and neurons after ischemic injury. PLOS One 2011; 6: e14724. 
3. Redell JB, Liu Y, Dash PK. Traumatic brain injury alters expression of hippocampal microRNAs: potential regulators of multiple pathophysiological processes. J Neurosci Res 2009; 87: 1435-1448.

4. Liu DZ, Tian Y, Ander BP, Xu H, Stamova BS, Zhan X et al. Brain and blood microRNA expression profiling of ischemic stroke, intracerebral hemorrhage, and kainate seizures. J Cereb Blood Flow Metab 2010; 30: 92-101.

5. Jimenez-Mateos EM, Henshall DC. Epilepsy and microRNA. Neuroscience 2013; 238: 218-229.

6. Siegel C, Li J, Liu F, Benashski SE, McCullough LD. miR-23a regulation of X-linked inhibitor of apoptosis (XIAP) contributes to sex differences in the response to cerebral ischemia Proc Natl Acad Sci USA 2011; 108: 11662-11667.

7. Selvamani A, Sathyan P, Miranda RC, Sohrabji F. An antagomir to microRNA Let7f promotes neuroprotection in an ischemic stroke model. PLOS One 2012; 7: e32662.

8. Stoica BA, Faden Al. Cell death mechanisms and modulation in traumatic brain injury. Neurotherapeutics 2010; 7: 3-12.

9. Youle RJ, Strasser A. The BCL-2 protein family: opposing activities that mediate cell death. Nat Rev Mol Cell Biol 2008; 9: 47-59.

10. Liu X, Kim CN, Yang J, Jemmerson R, Wang X. Induction of apoptotic program in cell-free extracts: requirement for dATP and cytochrome c. Cell 1996; 86: 147-157.

11. Susin SA, Lorenzo HK, Zamzami N, Marzo I, Snow BE, Brothers GM et al Molecular characterization of mitochondrial apoptosis-inducing factor. Nature 1999; 397: 441-446.

12. Jeffers JR, Parganas E, Lee $Y$, Yang $C$, Wang J, Brennan J et al. Puma is an essential mediator of p53-dependent and -independent apoptotic pathways. Cancer Cell 2003; 4 321-328.

13. Yakovlev AG, Di Giovanni S, Wang G, Liu W, Stoica B, Faden Al. BOK and NOXA are essential mediators of p53-dependent apoptosis. J Biol Chem 2004; 279: 28367-28374.

14. Engel T, Plesnila N, Prehn JH, Henshall DC. In vivo contributions of BH3-only proteins to neuronal death following seizures, ischemia, and traumatic brain injury. J Cereb Blood Flow Metab 2011; 31: 1196-1210.

15. Ambacher KK, Pitzul KB, Karajgikar M, Hamilton A, Ferguson SS, Cregan SP. The JNK- and AKT/GSK3beta- signaling pathways converge to regulate Puma induction and neuronal apoptosis induced by trophic factor deprivation. PLOS One 2012; 7: e46885.

16. Akhter R, Sanphui $P$, Biswas SC. The essential role of p53-up-regulated modulator of apoptosis (Puma) and its regulation by FoxO3a transcription factor in $\beta$-amyloid-induced neuron death. J Biol Chem 2014; 289: 10812-10822.

17. Zareen N, Biswas SC, Greene LA. A feed-forward loop involving Trib3, Akt and FoxO mediates death of NGF-deprived neurons. Cell Death Differ 2013; 20: 1719-1730.

18. Gilley J, Coffer PJ, Ham J. FOXO transcription factors directly activate bim gene expression and promote apoptosis in sympathetic neurons. J Cell Biol 2003; 162: 613-622.

19. You H, Pellegrini M, Tsuchihara K, Yamamoto K, Hacker G, Erlacher $M$ et al. FOXO3a-dependent regulation of Puma in response to cytokine/growth factor withdrawal. $J$ Exp Med 2006; 203: 1657-1663.

20. Sabirzhanov B, Zhao Z, Stoica BA, Loane DJ, Wu J, Borroto C et al. Downregulation of miR-23a and miR-27a following experimental traumatic brain injury induces neuronal cell death through activation of proapoptotic Bcl-2 proteins. J Neurosci 2014; 34: 10055-10071.

21. Sabirzhanov B, Stoica BA, Hanscom M, Piao CS, Faden Al. Over-expression of HSP70 attenuates caspase-dependent and caspase-independent pathways and inhibits neurona apoptosis. J Neurochem 2012; 123: 542-554.

22. Siman R, Mclntosh TK, Soltesz KM, Chen Z, Neumar RW, Roberts VL. Proteins released from degenerating neurons are surrogate markers for acute brain damage. Neurobiol Dis 2004; 16: 311-320.

23. Jimenez-Mateos EM, Engel T, Merino-Serrais P, McKiernan RC, Tanaka K, Mouri G et al. Silencing microRNA-134 produces neuroprotective and prolonged seizure-suppressive effects. Nat Med 2012; 18: 1087-1094.

24. Henshall DC. MicroRNA and epilepsy: profiling, functions and potential clinical applications Curr Opin Neurol 2014; 27: 199-205.

25. Ponomarev ED, Veremeyko T, Weiner HL. MicroRNAs are universal regulators of differentiation, activation, and polarization of microglia and macrophages in normal and diseased CNS. Glia 2013; 61: 91-103.

26. Mohite A, Chillar A, So S-P, Cervantes V, Ruan K-H. Novel mechanism of the vascular protector prostacyclin: regulating microrna expression. Biochemistry 2011; 50: 1691-1699.

27. Krol J, Busskamp V, Markiewicz I, Stadler MB, Ribi S, Richter J et al. Characterizing lightregulated retinal microRNAs reveals rapid turnover as a common property of neuronal microRNAs. Cell 2010; 141: 618-631.

28. Monteys AM, Spengler RM, Wan J, Tecedor L, Lennox KA, Xing Y et al. Structure and activity of putative intronic miRNA promoters. RNA 2010; 16: 495-505.

29. Ozsolak F, Poling LL, Wang Z, Liu H, Liu XS, Roeder RG et al. Chromatin structure analyses identify miRNA promoters. Genes Dev 2008; 22: 3172-3183.

30. He C, Li Z, Chen P, Huang H, Hurst LD, Chen J. Young intragenic miRNAs are less coexpressed with host genes than old ones: implications of miRNA-host gene coevolution. Nucleic Acids Res 2012; 40: 4002-4012.
31. Noshita N, Lewén A, Sugawara T, Chan PH. Akt phosphorylation and neuronal survival after traumatic brain injury in mice. Neurobiol Dis 2002; 9: 294-304.

32. Farook JM, Shields J, Tawfik A, Markand S, Sen T, Smith SB et al. GADD34 induces cell death through inactivation of Akt following traumatic brain injury. Cell Death Dis 2013; 4: e754.

33. Zhang X, Chen Y, Ikonomovic MD, Nathaniel PD, Kochanek PM, Marion DW et al. Increased phosphorylation of protein kinase $B$ and related substrates after traumatic brain injury in humans and rats. J Cereb Blood Flow Metab 2006; 26: 915-926.

34. Zhao S, Fu J, Liu X, Wang T, Zhang J, Zhao Y. Activation of Akt/GSK-3beta/beta-catenin signaling pathway is involved in survival of neurons after traumatic brain injury in rats. Neurol Res 2012; 34: 400-407.

35. Wu C-H, Hung T-H, Chen C-C, Ke C-H, Lee C-Y, Wang P-Y et al. Post-injury treatment with 7,8-dihydroxyflavone, a TrkB receptor agonist, protects against experimental traumatic brain injury via PI3K/Akt signaling. PLoS One 2014; 9: e113397.

36. Chen S-F, Tsai H-J, Hung T-H, Chen C-C, Lee CY, Wu C-H et al. Salidroside improves behavioral and histological outcomes and reduces apoptosis via PI3K/Akt signaling after experimental traumatic brain injury. PLoS One 2012; 7: e45763.

37. Freilich RW, Woodbury ME, Ikezu T. Integrated expression profiles of mRNA and miRNA in polarized primary murine microglia. PLoS One 2013; 8: e79416.

38. Kermer $\mathrm{P}$, Klocker N, Labes M, Bahr M. Insulin-like growth factor-I protects axotomized rat retinal ganglion cells from secondary death via PI3-K-dependent Akt phosphorylation and inhibition of caspase-3 In vivo. J Neurosci 2000; 20: 2-8.

39. Jeong J-K, Park S-Y. Transcriptional regulation of specific protein 1 (SP1) by hypoxiainducible factor 1 alpha (HIF-1 $\alpha$ ) leads to PRNP expression and neuroprotection from toxic prion peptide. Biochem Biophys Res Commun 2012; 429: 93-98.

40. Yeh SH, Yang WB, Gean PW, Hsu CY, Tseng JT, Su TP et al. Translational and transcriptional control of Sp1 against ischaemia through a hydrogen peroxide-activated internal ribosomal entry site pathway. Nucleic Acids Res 2011; 39: 5412-5423.

41. Bazarian JJ, Blyth B, Mookerjee S, He H, McDermott MP. Sex differences in outcome after mild traumatic brain injury. J Neurotrauma 2010; 27: 527-539.

42. Ge X-T, Lei $P$, Wang H-C, Zhang A-L, Han Z-L, Chen X et al. miR-21 improves the neurological outcome after traumatic brain injury in rats. Sci Rep 2014; 4: 6718.

43. Han Z, Chen F, Ge X, Tan J, Lei P, Zhang J. miR-21 alleviated apoptosis of cortical neurons through promoting PTEN-Akt signaling pathway in vitro after experimental traumatic brain injury. Brain Res 2014; 1582: 12-20.

44. Xiong Y, Mahmood A, Chopp M. Animal models of traumatic brain injury. Nat Rev Neurosci 2013; 14: 128-142.

45. Fox GB, Fan L, Levasseur RA, Faden Al. Sustained sensory/motor and cognitive deficits with neuronal apoptosis following controlled cortical impact brain injury in the mouse. J Neurotrauma 1998; 15: 599-614.

46. Loane DJ, Pocivavsek A, Moussa CE, Thompson R, Matsuoka Y, Faden Al et al. Amyloid precursor protein secretases as therapeutic targets for traumatic brain injury. Nat Med 2009; 15: $377-379$.

47. Yakovlev AG, Ota K, Wang G, Movsesyan V, Bao WL, Yoshihara K et al. Differential expression of apoptotic protease-activating factor-1 and caspase-3 genes and susceptibility to apoptosis during brain development and after traumatic brain injury. J Neurosci 2001; 21: 7439-7446.

48. Stoica BA, Movsesyan VA, PMt Lea, Faden Al. Ceramide-induced neuronal apoptosis is associated with dephosphorylation of Akt, BAD, FKHR, GSK-3beta, and induction of the mitochondrial-dependent intrinsic caspase pathway. Mol Cell Neurosci 2003; 22: 365-382.

49. Jimenez-Mateos EM, Bray I, Sanz-Rodriguez A, Engel T, McKiernan RC, Mouri G et al. miRNA expression profile after status epilepticus and hippocampal neuroprotection by targeting miR-132. Am J Pathol 2011; 179: 2519-2532.

50. Irizarry RA, Bolstad BM, Collin F, Cope LM, Hobbs B, Speed TP. Summaries of Affymetrix GeneChip probe level data. Nucleic Acids Res 2003; 31: e15.

51. Gautier L, Cope L, Bolstad BM, Irizarry RA. affy—analysis of Affymetrix GeneChip data at the probe level. Bioinformatics 2004; 20: 307-315.

52. Livak KJ, Schmittgen TD. Analysis of relative gene expression data using real-time quantitative PCR and the 2(-Delta Delta C(T)) Method. Methods 2001; 25: 402-408.

53. Stoica BA, Movsesyan VA, Knoblach SM, Faden Al. Ceramide induces neuronal apoptosis through mitogen-activated protein kinases and causes release of multiple mitochondrial proteins. Mol Cell Neurosci 2005; 29: 355-371.

54. Engel T, Caballero-Caballero A, Schindler CK, Plesnila N, Strasser A, Prehn JH et al. $\mathrm{BH} 3-$ only protein Bid is dispensable for seizure-induced neuronal death and the associated nuclear accumulation of apoptosis-inducing factor. J Neurochem 2010; 115: 92-101.

55. Landshamer S, Hoehn M, Barth N, Duvezin-Caubet S, Schwake G, Tobaben S et al. Bid-induced release of AIF from mitochondria causes immediate neuronal cell death. Cell Death Differ 2008; 15: 1553-1563.

56. Zhao Z, Loane DJ, Murray MG 2nd, Stoica BA, Faden Al. Comparing the predictive value of multiple cognitive, affective, and motor tasks after rodent traumatic brain injury. J Neurotrauma 2012; 29: 2475-2489.

57. Kabadi SV, Stoica BA, Hanscom M, Loane DJ, Kharebava G, Murray li MG et al. CR8, a selective and potent CDK inhibitor, provides neuroprotection in experimental traumatic brain injury. Neurotherapeutics 2012; 9: 405-421. 